Volume 17, Number 1, Winter 1988 ISSN 0710-4340

The Future of Educational Technology Don Beckwith

Computer-Aided Personalized System of Instruction for the Virtual Classroom W. Kinsner

J.J.Pear

Computerized Television: Technology Overshadows Aesthetics Nikos Metallinos

The Renfrew Quality Education Project: Teachers' Views After the First Year DonnaSharon

An AMTECPublication 


\section{Canadian Journal of Educational Communication}

\section{Volume 17, Number 1 Winter 1988}

\section{Editor}

Robert M. Bernard

\section{Assistant Editor}

Jacques LeCavalier

\section{Production Manager}

May Geneva, WRITEWORKS

\section{Editorial Assistant}

Liidy Amato

\section{Production Assistant}

Helen de Gourville

\section{Column Editors}

Richard Ellis, From the Educational

Communication and Technology

Periodicals

Len Proctor, Microware Review

Rose Bene, Book Reviews

ISSN $0710 \cdot 4340$

The Canadian Journal of Educational Communication is published quarterly by the Association for Media and Technology in Education in Canada; 500 Victoria Road North; Guelph, Ontario N1E 6K2; Canada: Attention: Mr. Ron Eyre, Secretary/Treasurer. Notification of address change should be sent to the above. All articles are copyright by AMTEC and may be reproduced for non-profit use without permission provided credit is given to CJEC. Back issues of CJEC are $\$ 10$ Canadian and may be obtained by contacting the Editor. CJEC is indexed in the Canadian Education Index and ERIC.

Second Class Mail Registration No. 6956

\section{ARTICLES}

Perspective

The Future of Educational

Technology

Don Beckwith

Computer-Aided Personalized

System of Instruction for the

Virtual Classroom

W. Kinsner

J. J. Pear

Computerized Television:

Technology Overshadows

Aesthetics

Nikos Me tallinos

\section{PROFILE}

The Renfrew Quality Education

Project: Teachers' Views After

the First Year

Donna Sharon

\section{COLUMNS}

Microware Review

Guest Editor:

Earl Misanchuk

From the Educational

Communication and

Technology Periodicals

All correspondence should be addressed to:

Dr. Robert M. Bernard, Editor

Education Department

Concordia University 1455 de Maisonneuve Blvd. W. Montreal, PQ, Canada H3G 
In Future Issues

Computer Alliances for

International Faculty

Development

Miriam K. Mills

Televised University Teaching:

Cost Analysis of a Laboratory

Class

Ruth C. Mackay

E. Joyce Carver

Introductory Accounting on DUET: A Comparative Evaluation Diana R. Carl

Bruce Densmore

Individual Differences in the Self-Regulation of Learning Emerging from Think Aloud Protocols

P. R. J. Simons

\section{CJEC ORDER FORM}

CJEC is free to members of AMTEC. However, many prefer to order the journal separately, and may do so by completing the form below:

(Name)

(Address)

$\$ 40.00$ (Cdn.) annual subscription

New Subscriber

Renewal

Please send me information about AMTEC and a membership form.

CHANGE OF ADDRESS

Send this form to:

Mr. Ron Eyre

AMTEC

500 Victoria Road North Guelph, Ontario N1E 6K2

Canada Printing Services. 


\section{Perspective}

\section{The Future of Educational Technology}

\section{Don Beckwith}

\section{INTRODUCTION}

What we need is a transformation, not just a reformation of the educational system. We will prepare Master's students for jobs that don't exist and look for school systems with the vision to hire them. We'll call them "Instructional Transformers" and their job will be to guide the learning of our children (Welliver, cited in Middendorf \& Coleman, 1987)

Welliver's visionary projection epitomizes the expectation of altruistic dream fulfillment that has drawn people to the field of educational technology for years. Educational technology is a winner. Upon encountering the field one immediately senses the powerful promise of potential. Within educational technology resides the potential for better schooling, better learning, better transmission of information, better interactive communication, better worlds.

Educational technologists can be recognized by the stars in their eyes. They know they are sitting on the most explosive potential of the century. Theirs is the apex of innovative motivation. Whether they are fashioning leaming environments, creating media, designing instruction or effecting research and theory, educational technologists have a dream-a dream that can sustain them, and those they touch, well into the next century. As Finn (1964) prophesied, "the educational future will belong to those who can grasp the significance of instructional technology" (p. 26).

With the power of the systems approach, the promise of mastery learning and the potential to subsume and redirect all relevant resources, educational technology can effect the transformation of learning processes and learning outcomes. Further, if it is accepted that improved learning can improve individuals and that improved individuals can effect improved environments, educational technology is a vanguard of social transformation. Educational technology is visionary, for its base, its focus, its vantage

Don Beckwith is Visiting Associate Professor of Educational Technology at Concordia University. 1455 de Maisonneuve Blvd. W., Montreal, PO H3G 1M8. This paper was invited and therefore not subject to the normal review process. 
point, its lofty goals are all grounded in the future. Its dream is the transformation of the way things are to the way things could be.

But the dream, while ever present, remains only a dream. The power, promise and potential of educational technology have not been realized. Resultingly, mild insecurity and disappointment have been replaced by unrest and discontent, The focus has turned from transformational leadership to survival within the status quo. And the voice of discontent is getting louder and more persistent.

Much of the discontent can be attributed to the realization that educational technology has not yet assumed its predicted third stage of evolution. Analyses of the past and future essences of educational technology (e.g., Davies, 1978) have determined three levels of evolution. The past has been described as the tools approach (Educational Technology I), i.e., the application of audio-visual devices to the improvement of teaching. The present has been described as the systematic(1) approach (Educational Technology II), i.e., the development and application of methodological, rule-based processes to the facilitation of learning. The future has been described as the systemic' approach (Educational Technology III), i.e., the creation of unified and dynamic wholes (from previously separated components) to effect the transformation of leaming. The field dreams of the ideal of Educational Technology III while operating within the status quo confines of Educational Technology II.

The discontent with mere survival within the level of the systematic approach, however loudly voiced and/or solution oriented, has been insufficient to force the field to the level of the systemic approach. The mission and the belief in the mission remain - to transform the learning process to a level that can only at present be imagined. Just as a master coach can transform individual teenagers into an Olympic medalist team; just as a master architect can stretch the capabilities of each construction team; just as a master film director can transform almost any assortment of people, things and processes into a vibrant and scintillating whole - so too can a master educational technologist systemically structure environments to effect higher and higher levels of cognitive ability. Instead, the status quo of Educational Technology II appears to be guaranteeing its survival at the expense of the realization of Educational Technology III.

The purpose of this Perspective is to review the mounting discontent (and its imbedded solutions) in order to determine the traps that must be avoided and the pathways that must be created so that educational technology can force its evolution to the systemic approach and the then-reachable dreams beyond.

\section{THE DISCONTENT}

The discontent within the ranks of educational technologists is not new, nor is it surprising. A future- and ideal-oriented field will, by definition, be discontented with the present, the status quo. Whereas the discontent of the past focused on the

(1) 'The words 'systematic' and 'systemic' come from different roots. The former from the Latin, with a nuance of order or interval; and thelatter from the Greek, with a nuance of organized whole" (Davies, 1984, p. 9). 
nonrealization of Educational Technology III, however, the more recent discontent appears to be focused on the difficulty of surviving at the level of Educational Technology II. Concern has shifted from the future of learning to the future of educational technology. Moreover, for the past ten years the latter concern has increased in tempo, breadth and frequency. Postulates abound on why educational technology has not yet realized its transformational potential. Proposed solutions to the problem are even more prevalent. These solutions, however, especially ones that purport to effect short-term survival, may, in fact, effect a continuation of the problem.

Finn (1955) warned that unless the field creates and communicates, throughout society; a public philosophy that is adequate for the times, "we can well disintegrate . . . we can become so immersed in trivia that a scientific dictatorship is inevitable" (p. 252). While this warning was targeted at a field that was at the time struggling to evolve from Educational Technology I to Educational Technology II, it remains valid for the struggling emergence to Educational Technology III.

Expanding on Finn's concern years later, Silber (1970) suggested that educational technologists did not even know what field they were in, that they had not communicated to themselves - much less throughout society - either the field's conceptualized purpose or even the interrelations of the components of the system called educational technology.

Torkelson (1977) reviewed what educational technology had accomplished and had yet to accomplish. Still needed, he suggested, were for the field a) to apply its intellectual technique directly to the benefit of humankind, by, for example, encompassing "value systems and idiosyncracies of individuals in the large purposes of schooling and society" (p. 357); b) to integrate the combined energies of its subgroups to common problems, such as the lack of an agreed-upon path and continuity for future inquiry, and the distance between the practitioner and researcher; and c) to constantly challenge itself by asking the "blunt, yet critical question: SO WHAT!" (p. 358).

Clark (1978) criticized graduate programs for producing practitioners rather than scholarly inquirers; and faculty for conducting too little research, teaching inappropriate research skills, holding experimental design and data analysis skills in low esteem, and for allowing soft-money contracts to control the focus of doctoral programs.

Silber (1978) chided that unless educational technology overcame its problems i.e., a) the lack of proactive synthesis of the subprofessions within the field, due to the restricted conceptual frameworks of the membership of each; b) the failure to effect or even recognize our potential impact on the educational system; c) the concern with the means rather than the ends of education, and therefore the nonenforcement of the field's ethical and value positions; d) the inappropriate and limited focus of research; e) the low quality of professional communication among educational technologists; f) the lack of understanding of the field's conceptual framework; and g) the inadequacy of leadership development efforts - "the profession will remain only partially developed or, perhaps, regress to a less fully developed stage" (p. 184), i.e., a subservient rather than a leadership role.

Torkelson (1980) urged that educational technologists move away from reductionist research (which could be said to typify the systematic approach of Educational 
Technology II) and toward constructionist research (which could be said to typify Educational Technology III).

Heinich (1984) placed the blame for educational technology's slower than desired evolution partly on the shoulders of those in other fields who reject our cause, but mostly on our own shoulders for a) creating alliances with those who have neither the power nor inclination to effect change; b) being blind to what-should-have-been obvious institutional constraints; c) allowing vested interests to interfere with scholarly inquiry; d) failing to distinguish "between our administrative 'home' and our intellectual foundations" (p. 73), thus fostering the inhibition of intellectual freedom; e) artificially restraining our technology to fit institutions within which it is being applied, f) narrowing our research focus on such as learning gains rather than exploring the "system effects of technology" (p. 76), i.e., emphasizing conclusion-oriented research over decision-oriented research; g) trying to apply established but inappropriate research questions, designs and techniques to systemic issues; and h) failing to "produce" sufficient reflective, thinking educational technologists. He further labeled educational technology a craft rather than a profession (again characteristic of the systematic approach of Educational Technology II).

Clark (1984) suggested that educational technology graduate programs have focused on instructional design models and procedures at the expense of the mindset of science and the tools of research, resultingly reducing the number of graduates who have the independent and original inquiry skills and the devotion to keep our field alive and well.

Hlynka and Nelson (1985), building from Davies' (1978) threefold definition of educational technology (the tools approach, the systematic approach and the systemic approach), presented an argument for viewing the field as a metaphor in order to realize a tripartite system which could sustain a creative productivity through its synergy.

Winn (1986), echoing a host of prior discontent with research in educational technology (e.g., Becker, 1978; Beckwith, 1984; Clark \& Snow, 1975; Koetting, 1983; Salomon \& Clark, 1977) stated that we are not only addressing the wrong research questions but also are applying inappropriate research methodologies. And Torkelson (1987) called for an end to the use of static research models in the study of dynamic learners and learning processes.

Gagne (1987) regretfully reminded us "that instructional design is not a part of the established order" (p. 20) in industry, military or universities, and warned that the valuable technical knowledge that instructional designers have "must be guarded from contamination, and not be compromised by the various influences of the marketplace" (p. 20).

Clark (1987) suggested that in order for us to become the world's third profession - after medicine and engineering - we must emulate the first two professions.

Echoing Heinich's (1984) concerns, he said that until we do so, we will remain a craft.

At the recent (1987) conference of Professors of Instructional Technology and Development (PIDT), 85 professors from the U.S. and Canada shared a weekend of informal presentations and discussions. In steady succession, throughout the conference, concerns about the survival of educational technology were expressed, and a wide array of "solutions" were traded. Rossett (1987), for example, traced her 
department's success at finding new, alternative and amazing markets, during the late 70's and early 80's, primarily in business and industry. "It was easy. It was also seductive" (p. 1), but now that the school market is beginning to resuscitate itself, we must, she suggested, for survival (translated in terms of monetary and administrative support for faculty and equipment), be ready to balance the needs of our diverse markets.

Bratton (1987) once again offered a plan for certification as the solution to our problem, the premise being that through the national and international certification/ accreditation of educational technology graduates and graduate programs, quality and survival will be assured. By following the paths of such as the National Board of Medical Examiners and the Institute of Industrial Engineers, educational technology, too, could emerge as a respected profession.

Walter Dick offered the Florida State University model of linking, inseparably, educational technology and educational psychology in our graduate programs in order to do better what teacher education purports to do. Canelos (1987) offered the Pennsylvania State University example of working with and for departments of engineering, which are currently receiving large development grants and in need of instructional design consulting. Schwen (as cited in Middendorf \& Coleman, 1987) suggested the development of an educational technology degree to "rock the boat of regular teacher education" (p. 4). Barry Bratton proposed that educational technology needed some type of continuing education system so that graduates can keep up with the field. (Perhaps this too could be accredited.)

Caffarella and Sachs (1987) announced the forthcoming publication of Doctoral Research in Educational Communication and Technology, conceived to "help the profession to identify invisible colleges and research trends, (for) by building upon the research of others, future researchers can advance the field more collectively than could be done by one individual working in isolation" (p. 3).

A large number of participants expressed concern about the next generation of educational technology professors, since very few graduates opt for academia over the higher-paying corporate world. In fact, this worry seemed to pervade the conference as an undercurrent theme. Such comments as, ". . . f for those who will sit in these chairs at future meetings . . . "; " . . f for those who will follow us . . .; "very few of our graduates are interested in our jobs, jobs in higher education"; "we must do more to emphasize the positive aspects of professorship and deemphasize the negative aspects" were sounded and echoed throughout the weekend. Another question was posed more than once: "Why do most college of education faculty view educational technology and instructional design endeavors as superficial, unprofessional, training rather than education, or any of the other negative comments often expressed?" Again, the concern was that of survival - survival of the professors of educational technology, survival of the field of educational technology.

Throughout the presentations and discussions, the underlying questions of "who are we", "where do we want to go", "how can we best affect the world?" (Middendorf \& Coleman, 1987) were omnipresent. To the extent that one can judge a field by the words and actions of the professors within that field, it would appear that educational technology is undergoing a period of anxiety, a temporary loss of focus/dimction/raison

Silber's (1971) old question: "What field are we in, anyway?" is resurfacing in a number of interesting and, perhaps, frightening ways. 
The discontent expressed in publications, presentations and conversations is clear, and it is pervasive. We are not being complacent about the situation. Solutions are being offered. Solutions are being applied. But these very solutions may be the seeds of our own infertility. If we are to survive, purposefully, as the cutting-edge field of our original vision, there are some solution-related traps that must be avoided.

\section{THE TRAPS}

The three major traps (Compromised Integrity, Status Quo Adherence, and Solidification) are presented as separate categories to ensure comprehensiveness and to facilitate discussion. The categories (and their sub-categories) are not intended to be seen as mutually exclusive. Approach them as a set of interrelated and interdependant traps.

\section{The Trap of Compromised Integrity}

The trap of Compromised Integrity can be found in three forms: a) Innovation affiliation, b) Greener pastures, and c) Political expediency.

Innovation affiliation. This trap is realized as the temptation to define learning and instructional problems in terms of the latest innovative 'solutions' rather than to create appropriate solutions to pre-addressed problems. Whether the ensnarement is in the form of 'blind' adoption of hardware, software, methodology or structure, the bait is alluring. Within the shining, bright newness of the innovation resides hope. How many have not been swept away (at least momentarily) by the dreams embedded within videodisc technology (or substitute any other magnetic innovation)?

The innovation is there. It is tangible, public and can be put to use immediately. Further, since innovations tend to be popular, those who affiliate with them may also be popular, or at least be seen as people who are in step with important trends. There is also the hope of survival, with a new gimmick, a new thrust, we may be able to stay alive long enough to do what we really must and want to do.

For the above reasons - hope, convenience, popularity - the pressure will remain on educational technologists to adopt and incorporate the latest innovations. Some recent examples: Clark (1987) suggested that an educational technology graduate program should be structured along the lines of the latest problem-orientation models of medical education (operational\&d by such leaders as Harvard, McMaster and Maastricht); Rossett (1987) suggested that opportunity is here and now to teach computer literacy skills to all public school teachers, for we have the hardware, the expertise, and the desire has been communicated by governments and university administrators. Beckwith (1987) suggested that computer-mediated conferencing has the potential for effecting superior group problem-solving skills.

While there is nothing inherently wrong in hop-on-the-bandwagon suggestions such as these, the risks are threefold. First, looking for the cutting-edge in fields can have the effect of transforming a leader into a follower, constantly looking for the next innovation to latch on to rather than creating the cutting edge to lean out and lead from.

Second, while it is important for a cutting-edge field to be aware of and purposefully incorporate what is new and viable within its systemic framework, educational 
technology cannot afford to run the risk of defining itself (or letting itself be defined) through current phenomena By falling into this trap, educational technology has, inter alia, been defined as a field of equipment jockeys, Skinnerian behaviorists, media producers and computer software specialists. When the vanguard message is not strong enough, educational technology runs the risk of being defined by its most visible and tangible parts; it becomes just another nomadic craft following today's sun, hoping that a new sun to follow lies just beyond the horizon.

Third, the time and energy given to the adoption of innovations can deplete significantly the time and energy needed for goal realization. This phenomenon is especially relevant when there are so many tempting innovations on the marketplace. While educational technology is, by definition, a subsumptive field, i.e., it is systemically possible to incorporate all on the way to goal realization, history suggests that innovation affiliation has more often led to the divergent dissipation of desired goals.

Through innovation affiliation temporary survival may be guaranteed at the cost of identity, purpose, and cutting-edge leadership. Being on the cutting edge of positive change is not to be equated to latching on to what appear to be the current winners. When a field is truly operating on the cutting edge, the world comes to it. As true now as it was when the field first emerged, there is a need for a collective of educational technologists (balanced on the cutting edge) which, by its very integrity of systemic validity, demands followers.

Greener pastures. ". . . Leadership will have to come from individuals who do scholarly inquiry for its own sake, who do not have one eye (or both) constantly on the alert for the next consulting opportunity" (Heinich, 1984, p. 85).

Now that the consulting opportunities in medical education, public schools and much of higher education have been all but exhausted by educational technologists, and those opportunities in business and industry appear likely soon to follow suit, we are once again seeking greener pastures. Engineering, for example, has been touted as the ideal pasture for current and future grazing (e.g., Canolis, for engineering has the money and is in need of the services that educational technology can provide. There are potential contracts and internships galore, and even, it is said, possibilities to link academically in a variety of ways with departments of engineering in higher education. The obvious risk in falling into this trap is that of losing one's intellectual integrity by selling out to the highest bidder.

At three educational technology conferences in the past year people have been seen wearing T-shirts proclaiming, "We will do IT in your field". While on the way to becoming the world's third profession (after medicine and engineering) we might, instead, become part of the oldest profession.

Political expediency. In any educational technology endeavour, be it in academia or on the front line, there is the temptation to use political expediency to ensure temporary (and perhaps on-going) survival. Compromise, in the form of doing what is expected of us (by those who do not know what we are capable of or by those who know very well what we are capable of and feel threatened), instead of doing what we know must be done, is high risk behaviour.

While all educational technologists must deal with significant others who may in some way affect their destiny, the trap snaps shut when the time and energy expended 
satisfying the perceived desires/mandates of these significant others preclude the time and energy needed to satisfy the mission of educational technology. Compromise for political expediency is not a critical attribute of a cutting-edge field. Every instance of relinquishing the integrity of the cutting-edge ideal is one step closer to the status quo. Every realization of others' misconceptions (whether through their ignorance or awareness) is one step backward from the educational technology ideal.

Such steps may be rationalized with surface logic, e.g., "It's what the client (Substitute 'dean', 'boss', 'student', 'subject matter expert', 'employer') wants"; "These are our bread and butter courses"; "It's where the money is"; "If we don't, we'll be forced to amalgamate with Department X"; "By doing this, we'll generate FTE's (Substitute 'further contracts', 'student employment possibilities'.), and then we can do the important things we really want and need to do"; "the state/university/administration expects it"; "This is the way it is"; "This is the reality of the situation". The true reality, however, is that by accepting and submitting to "reality", the ideal is lost.

The compromise of political expediency can have a stifling effect on every aspect of educational technology - its programs, its graduates, its professional work, its goals. Yet the practice persists. In fact, the trap of political expediency has so exacerbated the ill-being of the field that radical "solutions" have been proposed. Heinich (1984), for example, so frustrated with educational technology's futile attempts at transforming the educational status quo, advocated that our place is on the side of management (rather than labor) so that a top-down coup may be effected. Schwen (cited in Middendorf \& Coleman, 1987), so fed up with the ineffectuality of teacher education, proposed the creation of an undergraduate educational technology program to compete directly with teacher education programs. Clark (1984), so discontented with the inability of educational technologists to do what they should be doing (i.e., scholarly inquiry) urged that educational technology faculty and students have a solid background in and mastery of science.

Awareness of the deleterious effects of political expediency, not the least of which is the radical reaction to these effects, is a necessary fiit step toward avoidance of the trap. The solution - minimizing the compromise - can follow. Other proposed "solutions", such as the above-mentioned, face yet another trap, that of Status Quo Adherence.

\section{The Trap of Status Quo Adherence}

This trap awaits in three guises: a) Emulation; b) Legitimacy; and c) Absorption.

Emulation. Educational technology emerged to fill a gap left by the status quo. Educational technologists were and remain dissatisfied with the efforts of established fields to effect positive, meaningful change. While dedicated to a transformation to the teaching-learning ideal, educational technology persists in seeking out other models to emulate, status quo fields to mimic, instead of forcing to realization Educational Technology III.

A case in point: It has been suggested that we emulate the two established professions - medicine and engineering (e.g., Clark, 1987) - so that we too may become a profession (or at least display the external trappings of a profession?) Can a 
edge field determined to transform the status quo risk emulation of established professions? When the medical profession dedicates itself to a transformation - from the repair of malfunction to the creation of steady-state health - it may be worthy of emulation. When the engineering profession dedicates itself to a transformation from minor modifications of and improvements to existing environments to the creation of ideal environments for living - it too may be worthy of emulation. It may be a very long wait.

If others must be emulated, let it be those who have successfully applied systemic creation to the continual transformation of outcomes. Two that come to mind are film directors and athletic coaches. Both have demonstrated a capability to create a steady progression of new and improved, transformed systems from the potential system components at hand.

Part of the motivation for emulation, it appears (e.g., Heinich, 1984), stems from the fear of scaring off or eliciting defensive behaviour from those who have a vested interest in the status quo. While we, for example, are careful not to present educational technology as a panacea, our hope that it could be keeps us going; we are careful not to present educational technology as the revolutionary, transformational rebel that it is. Change is our game, but we act as if we are part of the establishment. The waves from a rocking boat caught in the undertow pass without notice.

The other part of the motivation stems from the loneliness and anxiety that come with being on the cutting-edge. It is scary on the edge. A leader must look for direction and purpose from within and many times must gut it out on faith alone. Until the field accepts the systemic approach as the suprasystem/suprastructure that it is, educational technology will remain a craft or, at best, a technology with a science foundation, i.e., the systematic approach. To suggest that the systemic approach is scientific, is or should be based on the methods of science is folly. Educational Technology III, is a new breed which cannot draw on the principles of the status quo for its definition, operationalization nor evaluation

By limiting ourselves to the status quo structure, within which to fashion the means to our desired ends, we limit our findings to those of the status quo, for it is the status quo environment (in all its limited yet diverse applications) which has produced the status quo outcomes. Our everpresent dissatisfaction with such outcomes should force us to create our own viable systems rather than to emulate systematic models of proven insufficiency.

Legitimacy. Closely related to the trap of emulation is the trap of legitimacy. So intent are we at gaining and maintaining the reputation of a legitimate profession, we strive to look and act like the "legitimate" disciplines. The acceptable research in educational technology looks like legitimate research - legitimate, that is, for psychology, sociology, medicine. The journals of educational technology have the size and shape of legitimacy. Their contents, order, review procedures, presentational formats all strive for the look and feel of legitimacy. No matter that a very small percentage of educational technologists subscribe to these journals, they nonetheless convince us of their legitimate rigor, excellence, and worthiness. So, too, for the educational technology conferences, striving for the legitimate look and feel of an AERA or APA conference, forcing would-be presenters to take fewer chances and tow 
the party line. Is adherence to the status quo in terms of legitimacy worth the price of losing sight of our systemic goal and mandate?

One problem in striving for legitimacy is that only that which has already been legitimated is legitimate. If educational technology adopts the posture of the legitimate within the status quo, it relinquishes the opportunity - nay, right - to create new and better-suited legitimate postures. What makes for legitimacy in fields that focus their energies on the systematic discovery of what is cannot be the same as that which makes for legitimacy in a field that focuses its energies on the systemic creation of what could be. The legitimacy of an educational technology posture, whether we are examining graduate programs, research, development, production, dissemination, or whatever, can only be evaluated by systemic criteria. Our potential legitimacy lies in the systemic approach of Educational Technology III. It seems that the time is right to create our own legitimacy - a legitimacy that is modelled after the true experts in educational technology (i.e., the risk takers, the rule breakers, the system creators) - for we need the creation of legitimate systems designed specifically for all aspects of our field: research, development, programs, etc. Until this has been accomplished, yet another trap looms - that of being absorbed by status quo legitimates.

Absorption. Educational technology has done very well with respect to surviving. But this survival has been at the cost of attachment to and absorption by other fields. Educational technologists have become, over the years, teacher educators, faculty development specialists, medical educators, training consultants, to name but a few. Not only has our field attached itself to existing, successful fields and been absorbed by them in the process - each time redefining its identity (and losing a bit more of its original identity) - but it has also attached itself to emerging fields promising the prospect of survival. Fields such as open learning, organizational development, distance education, cybernetics (general systems), and human resources development come to mind.

At the PIDT conference telling questions arose time and time again: "Where do we turn now?" (now that the business and industry market is close to saturation), "To whom do we attach ourselves?". Trying to instill some optimism, many suggested that the time is ripe to look back to the public schools. After all, the predictions all suggest increasing enrollments. Here certainly is a chance to rebuild and restaff the media centers that flourished in the 60's and 70's, and to work with teachers and school boards on the reform and renewal of instruction and curriculum. Others put forth computer literacy within the university environment as the next obvious target. Still others suggested that educational technology needed to accelerate and increase its attachment with the military establishment. And perhaps the nonprofit sector (e.g., museums, libraries) holds some promise for attachment, absorption, survival.

Educational technology has unfortunately established itself as a field that can only survive via attachment to other fields. A potential cutting-edge field has defined and redefined itself through a series of parasitic associations rather than through its own goals for learning transformation. Our field has allowed itself to be used and to be seen as a means for effecting the goals of other fields (however worthwhile) rather than as a means to the worthwhile and legitimate goals of educational technology.

As a vanguard field, educational technology must think in terms of leadership risk 
rather than parasitic survival. Among other things, a cutting-edge field provides clear, desirable visions (if they still can be remembered) and means for achieving these. By reason, these visions are at best contrary to those imaged by non cutting-edge fields.

Hence, the risk. While the cutting edge is sharp and at times scary, the risk is far greater if someone else is allowed to hold the handle. While there may be untapped fields willing to absorb educational technology into an adjunct role, the ultimate consequence of the trap of absorption is the loss of the singular identity necessary to realize our unique potential to lead in the creation of ideals rather than to serve for the betterment of the status quo.

Status quo adherence has resulted in educational technology's chameleonesque behaviour for the past 25 years. At first glance, this may appear to be the epitomization of a vibrant, dynamic field. In fact, by jumping from one survival attachment to another and losing identity to each in turn - instead of creating a dynamism of self-realization - educational technology is sowing the seeds of staticity. While each new attachment may bring the excitement and envigoration of another breath of life, temporary survival is insufficient and unfullfilling. Only iron-jawed adherence to the ideals of educational technology can guarantee long-term survival, mission realization, and the ultimate in excitement and envigoration.

\section{The Trap of Solidification}

When, in education, the psychologist or observer and experimentalist in any field reduceshis findings to a rule which is to he uniformly adopted, then, only, is there a result which is objectionable and destructive of the free play of education as an art. (Heinich, 1984.p. 87)

Reducing findings to a rule can be said to be characteristic of the systematic approach of Educational Technology II. When finally achieved, the free play of education as an art, on the other hand, will be characteristic of the systemic approach of Educational Technology III. Through continued reduction to uniformly applied rules, educational technology can solidify at the status quo, relinquishing the systemic dynamism necessary for transformation to the ideal. By accepting a caged existence within the traps of Compromised Integrity and Status Quo Adherence, educational technology has sampled the bait of the ultimate trap of Solidification - ultimate because once that trap has sprung, the potential realization of Educational Technology III will be lost forever.

Evidence of solidification is everywhere. At the most foundational level, educational technology has solidified as a field that has yet to proclaim, widely and loudly, its public philosophy. The focus continues to bypass the ends to spotlight the means the means of survival (of the field, of the subgroups within), the means of research, the means of graduate programs, the means of educational technologists.

The energy needed to apply the intellectual techniques of educational technology to the betterment of humankind has been sapped by solidification within the mode of short-term survival. Thus the desired ends of our field are subverted to the desired ends of our survival benefactors.

The intent of the subgroups within educational technology to survive as separate, 
meaningful entities has precluded the desirable (from the systemic point of view) synthesis of these sub-groups into a dynamic, purposeful whole, capable of elevating the field to its destiny. Within the subgroups there is solidification as well. In instructional design, for example, the models that are touted are, with rare exception (e.g., Bmtton, 1977; Gentry \& Trimby, 1984; Goldman, 1984) systematic, rule-based, reductionist procedures, differing little one to another.

Graduate programs, too, have solidified - to a primary focus on instructional design models and procedures (Clark, 1984). The graduate programs of today appear to be clones of the cutting-edge programs of a decade ago; in examining current graduate programs, one is struck with the overwhelming sensation of deja vu. The only originality found is within those programs which have 'had' to implement innovative solutions to survive in academia. Moreover, acceptance of proposed certification and accreditation plans could effect total program solidification.

Research in educational technology has come close to solidification as an inappropriate and limited method of inquiry. The cementing of reductionist, conclusionoriented, static, systematic research models precludes the needed study and realization of systemic entities. Systemic ends cannot be attained via systematic means.

The motto of the trap of Solidification could be: "Let's not reinvent the wheel". While educational technology will neither benefit from the reinvention of the known wheel nor from the novel application of existing wheels, the determination to create something better than the wheel will freeze the closing jaws of the trap.

To remain on the cutting edge, educational technology cannot enjoy the false comfort of solidification, cannot allow the devolution of artful systemic approaches to uniformly applied systematic rules. Only by embracing the amorphousness of the systemic approach can educational technology ensure its necessary, future existence.

As educational technologists have discovered, the traps of Compromized Integrity, Status Quo Adherence and Solidification are easy to fall into. They can be alluring and captivating. They can appear to be logical and rightful pathways to follow. They seem to offer security and comfort It would be easy to suggest that educational technology just avoid the traps - easy, but misleading. For the traps to be successfully avoided, alternatives must be created - alternatives that serve as pathways to Educational Technology III and subsequent realization of the ideal.

\section{PATHWAYS}

As I see it, two things must be done in order to resolve the current educational technology dilemma: a) reaffirm and publicly proclaim the goal and philosophy of educational technology; and b) create systemic roles for educational technology, educational technologists, and research in educational technology.

\section{Goal and Philosophy}

In its quest for survival, educational technology has focused its energies on means rather than the end. The goal of educational technology, and its philosophical 
base, have been momentarily obscured by attention to such means as designing graduate programs, implementing instructional designs for clients, maintaining a piece of the teacher education pie, conducting "legitimate" research, disseminating hardware and software, fashioning learning environments, and gaining acceptance and support from those in authority. The goal is still there; it has just not been recently attended to or sought after. While never formally stated as such (but often implied), I submit that the goal of educational technology is the transformation of learners and the learning process. Our goal is at once a goal of vision and proactivity.

Heinich (1984) suggested that "survival depends on establishing our own intellectual identity" (p. 73). The first step in this direction is the public affirmation and proclamation of our goal - the transformation of learners and learning processes. No other field shares this goal. Other fields are trying to discover what learning is, to determine how learning occurs, to facilitate learning. Our own intellectual identity awaits realization through public affirmation.

Just as the goal of educational technology has been kept under wraps, so too has the philosophical base of educational technology been implied rather than directly communicated. The philosophy is inherent in the voiced discontent with the field. Simply stated: We believe that all learners can be transformed to the highest level of cognitive ability. With such a lofty goal and supportive philosophical base, an extremely powerful means is necessary to effect goal realization. We have that too - the systemic approach.

Once we have reaffirmed our philosophy, goal and means to ourselves, and then publicly stated them to society, we can get on with the business of creating systemic roles for educational technology, educational technologists and research in educational technology.

\section{The Role of Educational Technology}

If educational technology is to have a viable, meaningful and identifiable place in society it must assume the role that others have not and will not assume - the role of idealizer (i.e., one who creates the means to realize the ideals of learning). The systemic approach enables us to serve as the problem-solvers of the learning process, the dreamers and creators of new and more effective learner systems.

Educational technology must also assume the role of conscience of learning in all sectors. Ours is the responsibility for ensuring the strengthening of individual value systems, idiosyncratic uniquenesses. Ours is the responsibility for ensuring the realization of the ethical and value positions of educational technology. Since operating systemically requires control over all system components (including those of Educational Technology I and II) ours is the responsibility for management of learner and learning transformation.

\section{The Role of Educational Technologists}

If Educational Technology III is to emerge and work, every educational technologist must be capable of systemic operation, i.e., every educational technologist must be a scholar (in the broadest sense of the word), "someone prepared to examine his or her own field in terms of its basic premises, its status, and its place in the general scheme 
of things - a reflecting, thinking individual" (Heinich, 1984, p.86). Beyond this, educational technologists should be creative, proactive individuals, always aware of the current systemic level of our dynamic, upwardly-spiralling field, and creating the next systemic level. The ideal educational technologist is not one who follows all of the known rules, not even one who follows all of the known rules well. The ideal educational technologist is one who breaks the known rules and creates new rules, thus enabling accomplishment of systemic creation, the type of creation not possible through the application of known, status quo, systematic rules.

Instead of spending time and energy training graduate students for specific, known jobs, as Clark (1984) suggested is occurring too frequently, educational technology could be preparing students, as Welliver (1987) suggested, for jobs that do not yet exist. For this to be possible, graduates must be equipped with a) altruistic skills that go beyond job acquisition and maintenance, to the satisfaction of learning needs of self, others and educational technology; b) systemic directorship ability, i.e., the ability to create (the way a good athletic coach or film director does) viable systems to transform learning, to direct, from conceptualization through evaluation and reconceptualization, toward successive approximations of systemic realization: c) the ability to control and manipulate given means (and create needed means) to effect desired ends; d) the skill to break known rules and create appropriate new rules as needed, the application of which will lead to higher, more inclusive, and greater integrative levels of performance -just long enough to break those newly created rules and create even newer ones; e) the ability to determine valid learning needs, above and beyond those perceived by the learner and/or the client; f) the ability to evaluate their own performance, the performance of learners, and the performance of educational technology; g) the skill to offer alternatives to the status quo by defining and redefining the ideal: and h) the ability to think and act systemically in all situations.

To the extent that our graduates master these skills, our long-term survival (without resorting to the short-term survival traps of Compromised Integrity, Status Quo Adherence and Solidification) will be assured. Whether educational technologists assume the traditional jobs of systems managers, producers, instructional designers, human resources developers, evaluators or professors, or jobs that do not yet exist, the role assumed and performed must be that of a transformer of learning if the field is to survive and thrive on the cutting edge. When all educational technologists have assumed the role of transformer, the artificial boundaries between the subgroups within the field and between the researcher and practitioner will disappear, allowing educational technology to transform itself to the systemic field it must become.

A word about the intellectual colleagues of educational technologists: While the desired state for a cutting-edge field is for every individual within to possess and exhibit the above-mentioned skills, in every field there are a few individuals who are always on the cutting edge and beyond. These are the mavericks (the geniuses, perhaps), able to define true needs, set desirable goals, create viable means, and evaluate the effectiveness of performance. It is these individuals - from any field - who must be our intellectual kin, our models, our support group.

The role of the educational technologist is one of catalyst of optimism, aligned, at least in spirit, with others who are proactively trying to raise the roofbeams, to elevate 
the actualized potential of human performance. With the afore-mentioned skills in hand and with the intellectual kinship of these mavericks from other fields, each and every educational technologist will be drawn to and capable of systemic inquiry. But first the role of research in educational technology must be attended to.

\title{
The Role of Research
}

In keeping with the goal and philosophy of educational technology, the obvious role of research is to accept such charges as Bloom's (1984) "2 sigma" challenge (an unfortunate norm-referenced concept), i.e., to create systems that effect learner performance two standard deviations above the mean. (The systemic researcher might prefer the challenge of creating systems to effect leamer performance at the highest levels of affect and cognition.)

In order to accept this challenge, educational technology must first abolish the artificial distinctions between its subcomponents. With the systemic approach there can be no distinctions between research, development, evaluation, management, teaching, design, or learning. In Educational Technology III all are one system with one goal, one philosophy, one means, and one role to play. By fully incorporating all educational technology components into the research process, the problem of limitations and inappropriateness of systematic approach research to the study of dynamic systems is eliminated. In its place is a proactive, systemic approach with the high expectations that come with a strong goal orientation. The systematic exclusion and/or control of variables is replaced by the systemic inclusion of all variables. All educational technology components become proactive participants in the research process. The research question, "Let's see what happens" transforms itself, through the systemic approach, to the challenge, "Let's make it happen together". (See Beckwith, 1984, for a fuller discussion of one possible systemic research methodology.)

Winn (1986) building from his earlier work (1975) and the work of Beckwith (1983) on open system models of learners, suggested thar

\begin{abstract}
...if wecan createexpertinstructional design systems, itshould bepossible to createCA I systems that design themsel ves as they interact with students. In other words, the prescriptive principles embodied in an instructional theory would be discovered by the system asit became familiar with each student it wasteaching. In effect, a separatetheory of instruction would devel op for each student, offering theultimatein adaptiveinstruction. (p.351)
\end{abstract}

Imagine such to include all of the components of educational technology research, design, development, production, learners, teachers, evaluation, management, etc. - together operating as a system, to effect higher and higher levels of learning transformation. Imagine such a system to be the personal learning environment of your dreams - rich, vibrant, alive, dynamic, accelerating - an environment in which such as research and development, production and dissemination, and teaching and learning are fused so tightly together that transformation is activated and reactivated like coiled springs released from their solidifying compression. In rapid succession, the system knows, knows it knows, knows how it knows, knows how to control how it knows, knows how to improve how it knows, searches to know what and how it doesn't yet know, and knows how to improve what it knows (Ego, 1987). 
And such a systemic research model is possible - but only if the current systematic form is abandoned. As Heinich (1984) suggested, "When the linear extension of a technological form" (in this case, the systematic approach) "reaches its limits, an increase in scale can only occur when the form itself is abandoned" (p. 76); . . . "increasing the scale" (in this case by forcing evolution to the systemic approach) "increases the range of control" (p. 76). Increasing the range of control increases the likelihood of goal attainment, dream realization.

\section{CONCLUSION}

Educational technology has a powerful and worthy dream - a dream yet to be fulfilled. Resultingly, the discontent within the field is mounting. Centering on the inability of educational technology to transform itself from the systematic approach to the systemic approach, this pervasive discontent warns of three debilitating traps Compromised Integrity, Status Quo Adherence, and Solidification.

It is suggested that the pathways leading out of the dilemma are: a) the reaffirmation and public proclamation of the goal (the transformation of learners and the learning process) and philosophy (that all learners can be transformed to the highest levels of cognitive ability) of educational technology; and b) the substitution of the traps of the systematic approach with a systemic recreation of the roles of educational technology, educational technologists, and research in educational technology.

This accomplished, the significance of educational technology will finally be grasped, and the educational future will belong to us. How significant is educational technology? It could be said that if educational technology were medicine, health could be realized if educational technology were engineering, ideal living space could be realized; if educational technology were law, peace could be realized. Educational technology as itself can realize the highest levels of cognition and affect in individuals - individuals who, in turn, will be able to create health, ideal space and peace.

To fulfill its dream, educational technology must reclaim its rightful place on the cutting edge - constantly pushing upward to the next level of transformation, applying constructionism to what needs to be. While life on the cutting edge is, at best, uncomfortable, this is where the systemic, transformational field of educational technology must reside to realize its destiny.

\section{REFERENCES}

Becker, A.D. (1977). Alternative methodologies for instructional media research. Audio-Visual Communication Review, 25, No.2, 181-194.

Beckwith, D. (1984). A research methodology for studying the learner as a total system: A conceptual paper. Proceedings of Selected Research Paper Presentations. Research and Theory Division, Association for Educational Communications and Technology, Ames, IA. 
Beckwith, D. (1987). Group problem-solving via computer conferencing: The realizable potential. Canadian Journal of Educational Communication, 16(2), 89-106.

Beckwith, D. (1983, Fall). The nature of learners as total systems, with implications for research and instructional development: A theoretical/conceptual paradigm. Journal of Visual Verbal Languaging, 9-28.

Bloom, B.S. (1984). The 2 sigma problem: The search for methods of group instruction as effective as one-to-one tutoring. Educational Researcher, 13, 4-16.

Bratton, B. (1977, November). Instructional development and systems. Audiovisual Instruction, 22, 60 .

Bratton, B. (1987, May). International Board of Standards for Training, Performance, and Instruction. Paper presented at the annual conference of Professors of Instructional Design and Technology. Shawnee Bluffs, IN.

Caffarella, E.P., \& Sachs, S.G. (1987, May). Doctoral research in educational communication and technology: A directory of dissertations. Paper presented at the annual conference of Professors of Instructional Design and Technology. Shawnee Bluffs, IN.

Canelos, J. (1987, May). Educational technology: Intelligent life beyond the college of education. Paper presented at the annual conference of Professors of Instructional Design and Technology. Shawnee Bluffs, IN.

Clark, R.E. (1987, October). Media and technology: Their present and future roles in education and training. Paper presented to the Faculty of Educational Technology, Concordia University, Montreal.

Clark, R.E. (1984). "Where's the beef'?": A reply to Heinich. Educational Communications and Technology Journal, 32(4), 229-232.

Clark, R.E. (1978). Doctoral research training in educational technology. Educational Communications and Technology Journal, 26(2), 165-178.

Clark, R.E., \& Snow, R.E. (1975). Alternative designs for instructional technology research. Audio-Visual Communication Review, 23(4), 373-394.

Davies, I. (1984). Instructional development: Themata, archetypes, paradigms and models. In R.K. Bass \& C.R. Dills (Eds.), Instructional development: The state of the art, II, (pp. 9-17). Dubuque, IA: Kendall/Hunt Publishing.

Davies, I. (1978). Prologue: Educational technology: Archetypes, paradigms, and models. In J. Hartley, \& I. Davies (Eds.), Contributions to an Educational Technology. London: Butterworths.

Ego (1987). Groupthink: Consciousness. Conferencing System (CoSy). Guelph, ON: University of Guelph.

Finn, J.D. (1955). A look at the future of AV communication. Audio-Visual Communication Review, 3(4), 244-256.

Finn, J.D. (1964). The Franks had the right idea. NEA Journal, 53(4), 24-27.

Gentry, C.G., \& Trimby, M.J. (1984). Interface analysis of ID systems. In R.K. Bass \& C. R. Dills (Eds.), Instructional development: The state of the art, II (pp. 94-107). Dubuque, IA: Kendall/Hunt Publishing.

Goldman, H.D. (1984). Instructional system development in the United States Air Force. In R.K. Bass \& C. R. Dills (Eds.), Instructional development: The state of the art, II (pp. 470495). Dubuque, IA: Kendall/Hunt Publishing. 
Heinich, R. (1984). The proper study of educational technology. Educational Communications and Technology Journal, $32(2), 61-87$.

Hlynka, D., \& Nelson, B. (1985). Educational technology as metaphor. Programmed Learning and Educational Technology Journal, 22 (1) 1-15.

Koetting, J.R. (1983). Philosophical foundations of instructional technology. Proceedings of Selected Research Paper Presentations (pp. 416-440). Ames, IA: Research and Theory Division, Association for Educational Communications and Technology.

Middendorf, J., \& Coleman, S. (1987, August). The 1987 PIDT Conference. N ewsletter of the Division for Instructional Development, Association for Educational Communications and Technology, 17(1), 3-4.

Rossett, A. (1987, May). Forces affecting the development of the Department of Educational Technology at San Diego State University. Paper presented at the annual conference of Professors of Instructional Design and Technology. Shawnee Bluffs, IN.

Salomon, G., \& Clark, R.E. (1977). Reexamining the methodology of research on media and technology in education. Review of Educational Research, 47, 99-120.

Silber, K.H. (1970). What field are we in, anyhow? A udio-V isual Instruction, 15(5), 21-24.

Silber, K.H. (1978). Problems and needed directions in the profession of educational technology. Educational Communications and Technology Journal, 26(2),174-185.

Torkelson, G.M. (1977). AVCR One quarter century: Evolution of theory and research. A udio-V isual Communication R eview, 25(4), 317-358.

Torkelson, G.M. (1987). Perspective: Theoretical bases for research in media. Canadian Journal of Educational Communication, 16 (1), 3-9.

Torkelson, G.M. (1980, April). Research symposium. A paper presented to the Research and Theory Division of the Association for Educational Communications and Technology, Denver, CO.

Winn,W. (1986). Trends and future directions in educational technology research from a N orth A merican perspective. Programmed Learning and Educational Technology Journal. 23(4), 346-355. 


\section{Computer-Aided Personalized System of Instruction for the Virtual Classroom}

\section{W. Kinsner \\ J. J. Pear}

Abstract: This paper describes a computer-aided personalized system of instruction (CAPSI) and its implementations with regard to both on-campus and off-campus teaching. Four years of experience with the method have prompted a natural evolution of the system from a single terminal to multiple terminals, with direct and remote links, and electronic mailing and messaging. Local area networks are being considered to extend the system even further to allow stand-alone implementations of CAPSI. In a broad sense, the method

is conceptualized as a step toward the goal of involving the computer in the development of educational material and the evaluation of learning in a virtual classroom environment.

\section{INTRODUCTION}

In a classic paper, Keller (1968) launched a new approach to teaching at the postsecondary level called Personalized System of Instruction (PSI). Based on principles and procedures from the newly emergent field of the experimental analysis of behavior, founded by Keller's friend and colleague, B.F. Skinner (e.g., 1953 and 1954). the approach stressed: a) clear specification of the behavior to be modified; b) frequent and immediate reinforcement of the behavior; c) minimization of punishment: and d) selfpacing by the student. These principles had been incorporated earlier by Skinner (e.g., 1961), in his work on programmed instruction and teaching machines, in which students filled in critical words or phrases that were left blank in a short piece of text. However, Keller applied the principles to larger segments of behavior (See Keller \&

W. Kinser is an Associate Professor in the Department of Electrical Engineering at the University of Manitoba. J. J. Pear is a Professor in the Department of Pscyhology, also at the University of Manitoba. We thank Bernie Simand, Director of InterUniversities North (IUN), and Sam Shaw, former Director of IUN, for their support and encouragement in developing the off-campus teaching component of this project. Special thanks go to Frank Herzog for the initial coding of the program, and to Manix Leung for many improvements to the code. This work was supported in part by the University of Manitoba Academic Development Fund, the Natural Sciences and Engineering Research Council of Canada, and private funds. 
Sherman, 1982). Studies on PSI have shown it to be more effective in teaching specific material than other methods commonly used at the postsecondary level (Kulik, Kulik \& Cohen, 1979; Sherman, 1982).

Comparisons between traditional and other techniques of teaching and learning, including PSI, are made in the volume compiled by Sherman, Ruskin, and Semb (1982). A review of modem approaches to a more significant use of machines in design is given by Ehrmann and Balestri (1987). Another example of the extensive use of computer communication systems, and particularly computerized conferencing, in the formation of human community is given by Hiltz and Turoff (1978). A serious attempt to develop an authoring system for the computer-mediated learning environment is represented by NATAL (1981). In a more recent approach, knowledge representation and knowledge engineering are applied to intelligent tutors by Woolf (1987).

The method described in this paper represents a fundamental extension of PSI in which the above modem approaches can be folly applied. The method provides a basis for modelling, parameter estimation, optimization, and the use of knowledge engineering to improve its value to both the teacher and the student. To demonstrate the usefulness of the method, we first describe the principles of PSI, followed by computerization of PSI for on-campus and off-campus education, and an analysis of data obtained using the new method.

\section{PRINCIPLES AND PROCEDURES OF PSI}

The major distinguishing characteristics of PSI are as follows:

Clear specification of the behavior. In PSI, the behavior to be learned is specified as answering questions about or solving problems relating to the course material. For each course, a list of study questions or study objectives on the material is drafted, such that a student who can answer a large percentage of the questions or meet a large percentage of the objectives can be said to have mastered the course material. In addition to being given the study questions or study objectives, the student is informed exactly how mastery of the course material will be assessed.

Frequent and immediate reinforcement of the behavior. The course material is broken down into units that are small enough to ensure frequent reinforcement in the form of feedback on unit tests. Immediate feedback on the tests is provided by the instructor, by teaching assistants, and by other students (termed "proctors") who have mastered the material.

Minimization of punishment. The unit tests are designed to increase in difficulty gradually so as to minimize. the probability of failing a test, which is the most significant form of punishment in educational settings. In addition, the only penalty for not passing a test is that the student must restudy and attempt another test on that unit. Finally, the word "fail" is avoided since it produces conditioned emotional responses in many students.

Self-pacing by the student. For a variety of reasons, different people require different amounts of time to master a given subject matter. PSI takes account of this by 
permitting individual students to progress through the course at their own rates within the deadline set by the academic institution for the submission of final grades.

\section{COMPUTERIZATION OF PSI}

\section{CAPSI for On-Campus Learning}

PSI lends itself well to computerization because it is a highly systematic procedure. Development of a program for computer-aided PSI (CAPSI) has been an ongoing project at the University of Manitoba since 1983. The program has been described in detail elsewhere (Pear \& Kinsner, in press). A simplified diagram of the CAPS1 program is shown in Figure 1. The success of the program can be attributed to the finite-state modelling of all the transactions that take place during the course offered.

Briefly, the main function of the computer is to give tests to students who request them, to assign markers to completed tests, and to keep track of the progress of each student through the course. The program was initially designed for students to write their tests "off-line" using pencil and paper, since only two computer terminals could be obtained for the courses using CAPSI. Each test is marked by either the instructor, a teaching assistant, or proctors who are students enrolled in the same course and who have passed the units for the tests they are assigned to mark. To help ensure marking verification, two proctors are chosen to mark each test. If more than two eligible proctors are available at the time a student requests to have a test marked, the computer chooses the two who have proctored the fewest number of times. If there are more than two who have proctored the fewest number of times, the computer chooses randomly among them. The computer designates the instructor or teaching assistant to mark a test only if two eligible proctors are not available. Students receive points from the computer toward their final grade for acting as proctors, since serving in this capacity helps them to better learn the course material.

CAPS1 at the. University of Manitoba has been used in several different ways. The courses taught have included "Introduction to Psychology", "Behavior Modification Principles", "Behavior Modification Applications", "Learning Foundations of Psychology", and "Humanistic and Transpersonal Psychology" taught by J. J. Pear, "Introduction to Psychology" taught by J. J. Pear and J. H. Whiteley jointly, and "Experimental Child Psychology" taught by J.H. Whiteley. It is also being considered for teaching in engineering. The range of students in any given course has been from about 20 to 65 .

The method is independent of course content provided that the course material is structured appropriately for the subject matter. For example, typical study questions from a course on humanistic and transpersonal psychology might be as follows:

1) Why was humanistic psychology originally called "third-force psychology"?

2) Why were some third-force psychologists unhappy with the name "humanistic psychology" as the name for their movement?

3) According to Maslow, what are "peak experiences"? What can produce them? Describe a peak experience that you have had, including the circumstances under which it occurred. 


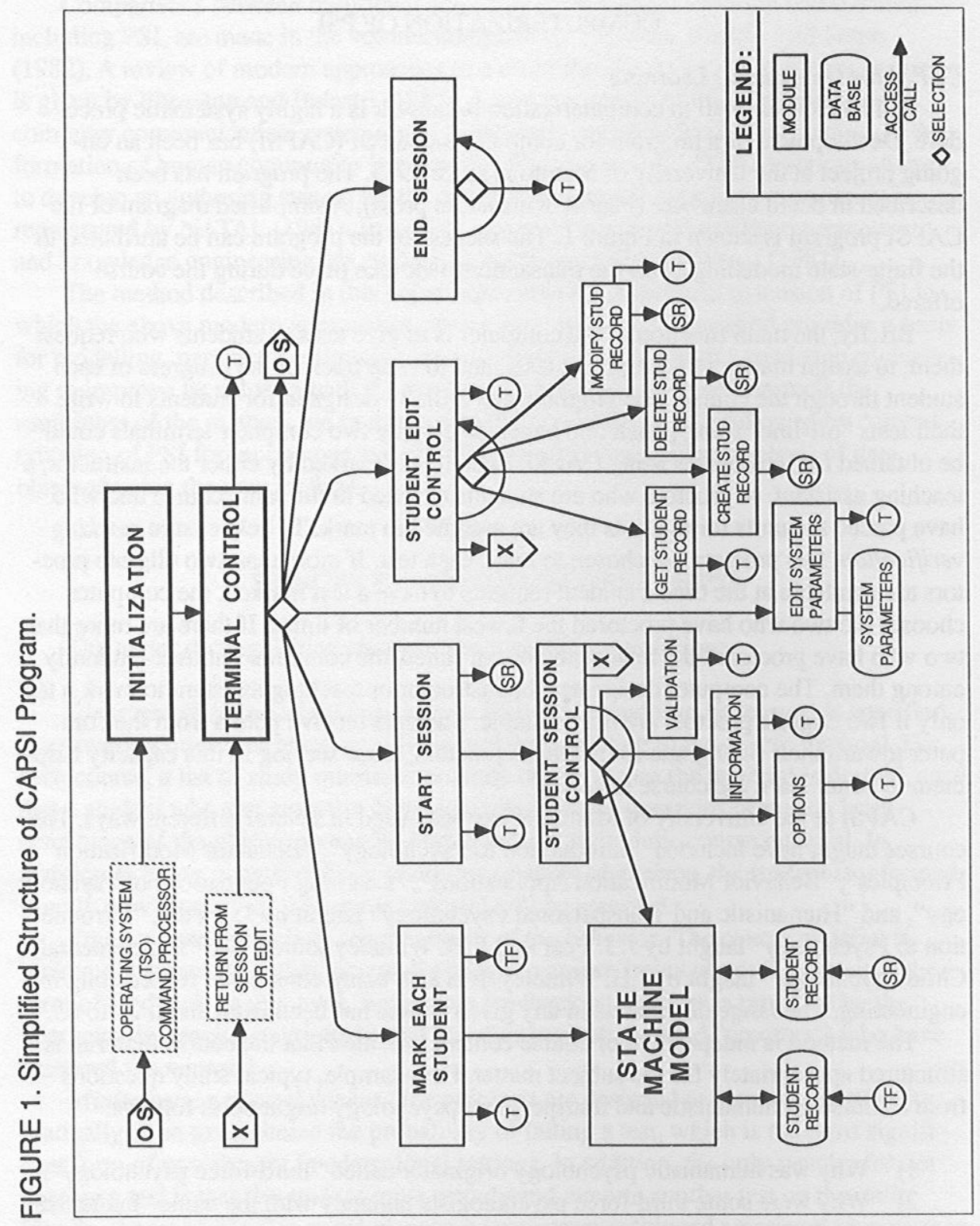


Typical study questions for a coarse on behavior modification might be:

1) Describe five distinguishing characteristics of behavior modification.

2) How does the behavioral approach to abnormal behavior differ from the medical model approach?

3) Describe two examples of positive reinforcement that you have encountered, one. involving a desirable behavior and one involving an undesirable behavior.

Other examples of behavior modification study questions can be found in the behavior modification text by Martin and Pear (1983) which was written specifically for a PSI approach, and which contains discussion relating to behavioral theory.

In the beginning, the CAPSI program could be run on only one terminal. This was a problem for courses having more than 50 students. There were long lineups of students to use the terminal in many classes, and students complained about the waiting time to obtain test questions and to have their tests marked. One solution to this problem was to add a second terminal, subdivide the class into two groups, and assign one group to each terminal. This had the disadvantage of preventing proctors who were available on one terminal from being assigned to mark tests given on the other terminal. Another solution that was tried was to assign each terminal to one of two different courses, and permit students to work on the terminal for their courses during the class period for either course. However, some students who could not come to both class periods felt that this gave an unfair advantage to students who could do so and who could, consequently, progress through the course more quickly and have more opportunities to improve their mark by proctoring.

In January, 1984, a multiuser form of the program was put into effect, so that students could access the program through either terminal. Lineups still occurred in large classes, especially near the end of the academic term, but the problem was greatly attenuated. In addition, a thiid terminal was introduced solely for the use of the instructor and teaching assistant. This permitted the instructor and teaching assistant to enter tests results immediately after the tests were marked, which reduced much of the congestion in large courses. Moreover, a command was provided for tbe instructor to print out the names of students who were writing tests at any given time. This was very useful for ensuing that students who were writing tests were in the section of the classroom that had been designated for that purpose, so that these students could be supervised more easily.

\section{CAPSI for Off-Campus Learning}

In addition to improving the implementation of the program in a classroom, the multiuser capability permitted a course taught by CAPSI to be offered in more than one location simultaneously. The obvious implications of this for off-campus teaching did not go unnoticed. Like most other major universities (e.g., Montgomerie, 1987), the University of Manitoba provides off-campus courses to people in communities distant from the university who, for various reasons, are unable to attend classes offered on the university campus. With budget cutbacks, paying travel expenses to instructors has become less feasible. A less expensive alternative is for an instructor to deliver lectures through voice (audio) teleconferencing equipment to students located in classrooms in 
a number of communities simultaneously (Robertson, 1986). In addition to direct or deferred voice, teleconferencing may also be achieved by using "electronic blackboards" or computer conferencing.

In the fall of 1985, a full-year Introductory Psychology course using CAPS1 and voice teleconferencing was offered from Winnipeg to Thompson, Manitoba - a community over $800 \mathrm{~km}$ north of the University of Manitoba. About 20 students participated from a classroom in Thompson. The classroom contained two phone lines -one accessed audio-teleconferencing equipment, while the other accessed the university's mainframe computer running the CAPSI program. Thus, students were in voice contact with the instructor and in computer contact with the CAPSI program. Tests marked by the instructor were marked over the phone and the results entered through the instructors's terminal in Winnipeg; tests assigned to proctors were marked in Thompson and entered through the computer terminal there. In addition, a teaching assistant was available in Thompson to supervise students and to mark some of the tests designated to be marked by the instructor or teaching assistant.

Due to the success of this course, another off-campus CAPS1 course - "Behavior Modification Principles" - was offered during the May-June intersession of 1985. This time the course was taught from Winnipeg to two locations - Thompson and Flin Flon, Manitoba. About eighteen students were enrolled in Thompson, and about 6 in Flin Flon. The procedure was essentially the same that had been used in the previous long-distance CAPS1 course, except that proctors marked tests over the phone when those tests were written by students at the other location. A side benefit of this procedure was that the instructor was able to listen in on the marking interchanges, and to make suggestions or corrections when it was helpful to do so. One of the students in the course supervised test writing in Flin Flon and, as in the previous long-distance CAPS1 course, a teaching assistant performed this function in Thompson.

During the 1986-87 academic year, two half-year off-campus courses using CAPS1 - "Behavior Modification Principles" and its sequel, "Behavior Modification Applications" - were offered in six Manitoba locations: Morden, Lac du Bonnet, St. Boniface, Stonewall, Virden, and Thompson. Because supervisors were not available at most sites to monitor students taking unit tests, more weight was placed on the midterm and final examinations than had been the case in previous CAPS1 courses. About 60 students registered for the first term course. Unfortunately, the necessary computer equipment was not present in the six sites at the time that the first-term course began. This led to a goal deal of confusion, and about 16 students dropped the course very early. Within a month, however, computer equipment was set up at all locations and 35 of the original 44 students who started the course completed it successfully. It was, however, necessary to schedule a number of extra classes to help students catch up to where they probably would have been had the computer equipment been available at the beginning of the term.

\section{Inclusion of Electronic $M$ ailing and $M$ essaging into CA PSZ}

At the beginning of the 1986-87 second-term off-campus course, students who had access to computers and modems (e.g., teachers who could use computer equipment 
located in their schools) were given the option to access the CAPS1 program on their own outside of the regularly scheduled class periods, and to use the electronic mailing system of the University of Manitoba's mainframe computer to mail their test answers to the instructor for marking. About ten of the 30 students in the course took advantage of this opportunity on a regular basis. The instructor marked and provided feedback within 24 hours on each test received through electronic mail. The electronic mailing system also proved useful for other communications regarding the course.

\section{Generalization of CAPSI to the Virtual Classroom}

During the 1986.87 academic term, CAPS1 was also used again to teach oncampus courses. In order to alleviate the congestion that tended to occur with the early system in large classes, extra classes were added and were managed by teaching assistants.

As a result of the experience with on-campus and off-campus teaching, a more general solution to this problem was implemented at the beginning of the 1987-88 academic year. In this implementation, on-campus as well as off-campus students are now permitted to access the program on their own and to use the electronic mail system to send their tests to the instructor, teaching assistants, and proctors. In effect, this eliminates the distinction between on-campus and off-campus courses as far as CAPS1 is concerned, because the location from which the computer is accessed is irrelevant to the functioning of the computer.

Since the physical boundary of the classroom vanishes, this form of CAPS1 facilitates the implementation of the concept of a "virtual classroom" (Hiltz, 1986) in which the physical classroom may be much smaller than the logical classroom. the analogy to the virtual memory and virtual machine concepts can also be applied to the method of structuring all the interactions between the students, proctors, teaching assistants, and instructor.

This new form of CAPS1 may use a number of different network topologies, including the two examples shown in Figure 2. As described in the previous sections, the star topology (Figure 2a) has evolved over the last four years, starting from a single on-campus terminal and a mainframe connected through a direct link. The configuration was later extended to include other terminals and microcomputers connected through remote links-from both inside and outside of the campus. The single computers can also be networked using a ring topology (Figure 2b). Such local area networks (LANs) can then communicate either with the mainframe or even between themselves alone, without the mainframe, as stand-alone CAPS1 systems. The use of LANs is of particular interest to remote locations, where access to the mainframe computer may be costly or unreliable.

Further extensions of CAPS1 will include: a) the development of an authoring system for generating PSI course material, study objectives, and test questions, and b) the creation of a knowledge base for assistance in marking tests. 'Ibis and other research in artificial intelligence will convert PSI into a new tool for the teaching and learning of design, as defined by Pear and Kinsner (in press). 
FIGURE 2. Two Network Typologies for CAPSI:

a) Star Typology; and b) Star-ring Typology.

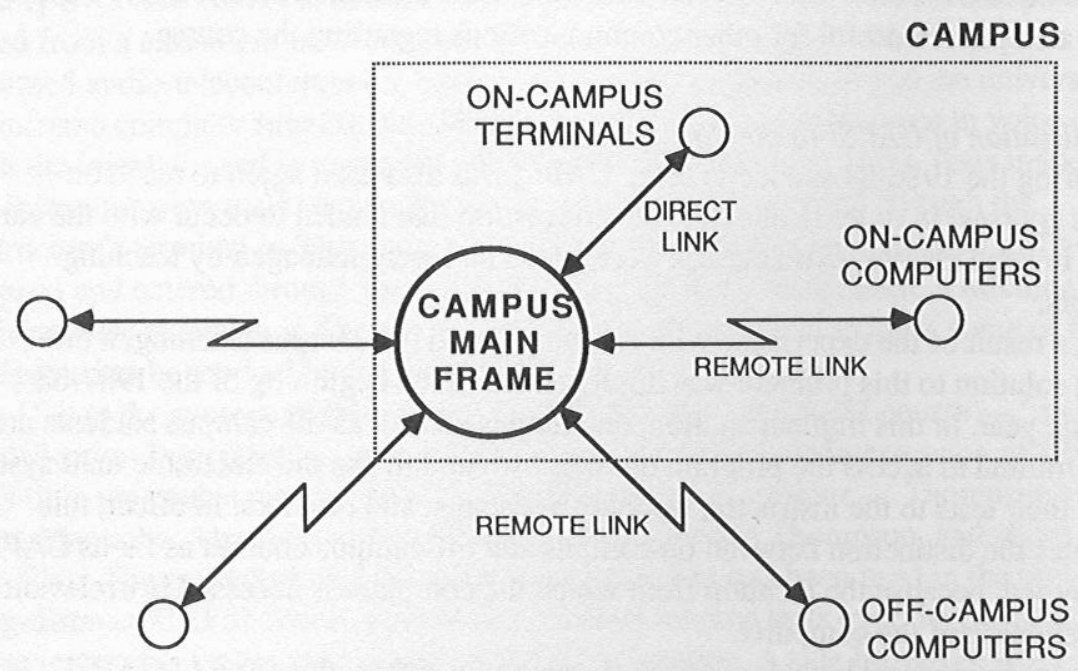

(a)

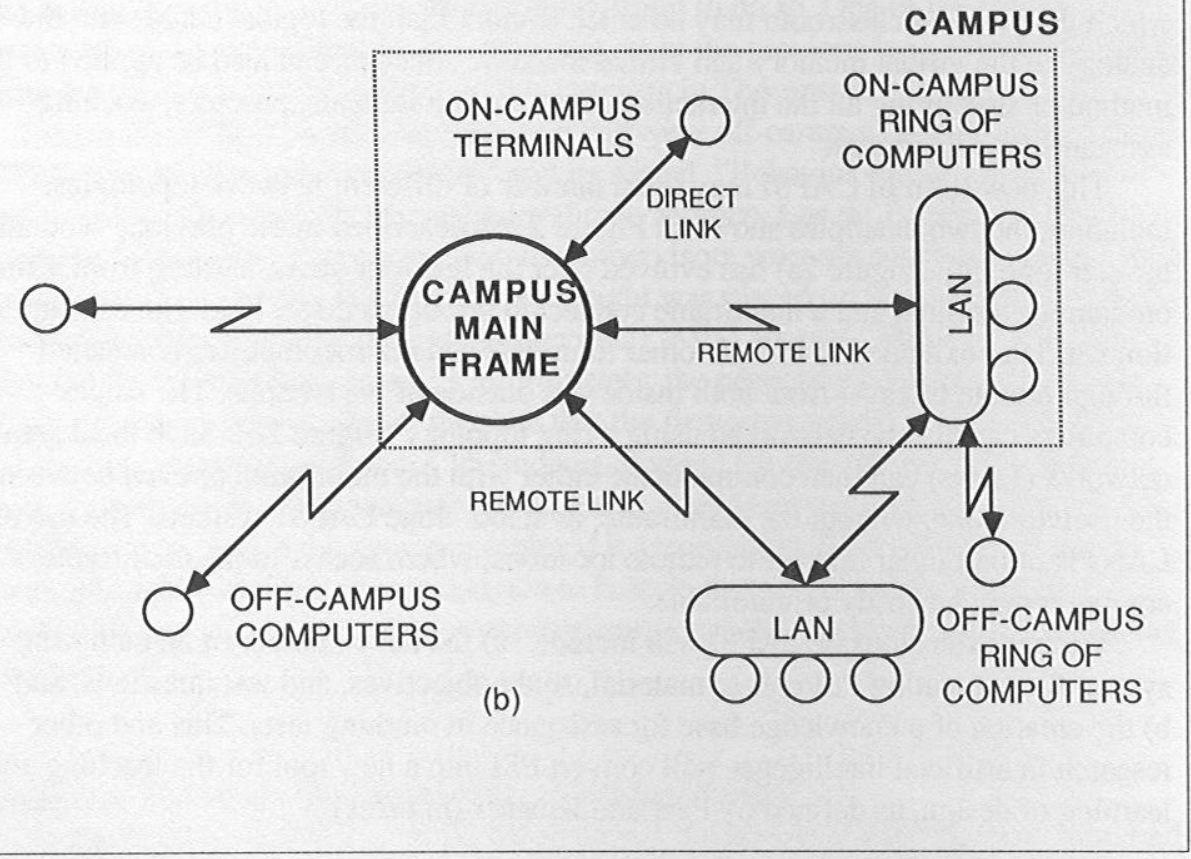




\section{STUDENT REACTIONS TO CAPSI}

Most students who complete CAPS1 courses have evaluated them to be as good as or better than courses using other methods. Many students are enthusiastic about the method, and feel that they learn better with this method than with the lecture method. Aspects of the course that students often rate as major strengths are the self-pacing and the opportunity to be a proctor. Students also like the fact that the material they are expected to learn is clearly specified by the study questions, that there are no "trick questions", and that it is possible to get a good grade if one learns tbe material. Aspects of the method that are often rated negatively are the absence of lectures or discussions, and the opportunities for cheating that are present in large courses with few supervisors. Technical difficulties regarding shortage of equipment have also been a source of complaint.

We find the positive evaluations by the students to be very encouraging and anticipate that the above negative aspects of CAPS 1 will be reduced or eliminated by the present use of electronic mailing. The incorporation of the electronic mailing system by CAPS1 should put students into closer contact with the instructor the teaching assistants, and other students, and thus pmvide the kinds of interchanges students expect to obtain from classroom lectures and discussions. Moreover, since students are now able to access the program at any time, class periods can be used for lectures and discussions for the purposes of supplementing the learning process rather than being viewed as the main method of teaching. Of course, since unit tests are unsupervised, the opportunity for cheating is increased. The solution to this potential problem is to give a low weight to unit tests and more weight to the midterm and final examinations in determining the final mark. Students are encouraged to understand that CAPSI is being used primarily for teaching rather than evaluation, and that students who do not follow the procedure properly will be unlikely to do well on the midterm and final examinations. Finally, permitting students to access tbe program at any time solves the above-mentioned problem of shortage of equipment in the classroom. Today, any campus has many computer terminals from which students can access the mainframe computer. Off-campus students also should have little problem obtaining access to computer terminals and modems. For example, such equipment exists in all school divisions in Manitoba, many of which appear to be willing to make it available for courses offered to members of their communities.

\section{DISCUSSION OF DATA}

An important feature of the CAPS1 program is that it saves data describing the interactions that occur during the entire course, including: all marking transactions, the type and result of each transaction, and the date and time of the transaction. These data can later be accessed and analyzed in any desired manner. Several examples are presented here of how these data can be used to provide information about the progress of students in the course and information about the functioning of the course itself.

\section{Student Performance}

Figures $3 \mathrm{a}, 3 \mathrm{~b}$ and $3 \mathrm{c}$ show the performance of

typical students A, B, and C, 
FIGURE 3a. Examples of Test and Proctoring Scores (solid line: test score; dotted line: proctoring score). Student A. Total Test Score $=13$; Total Proctoring Score $=4.75$.

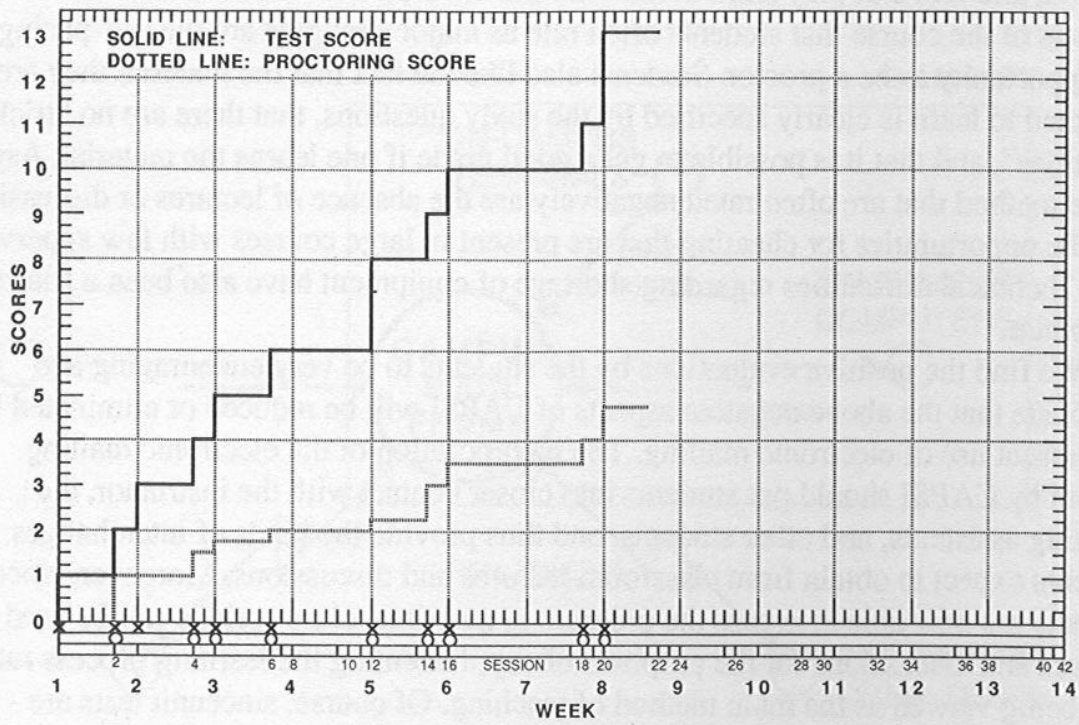

FIGURE 3b. Examples of Test and Proctoring Scores (solid line: test score; dotted line: proctoring score). Student B. Total Test Score $=13$; Total Proctoring Score $=6.75$.

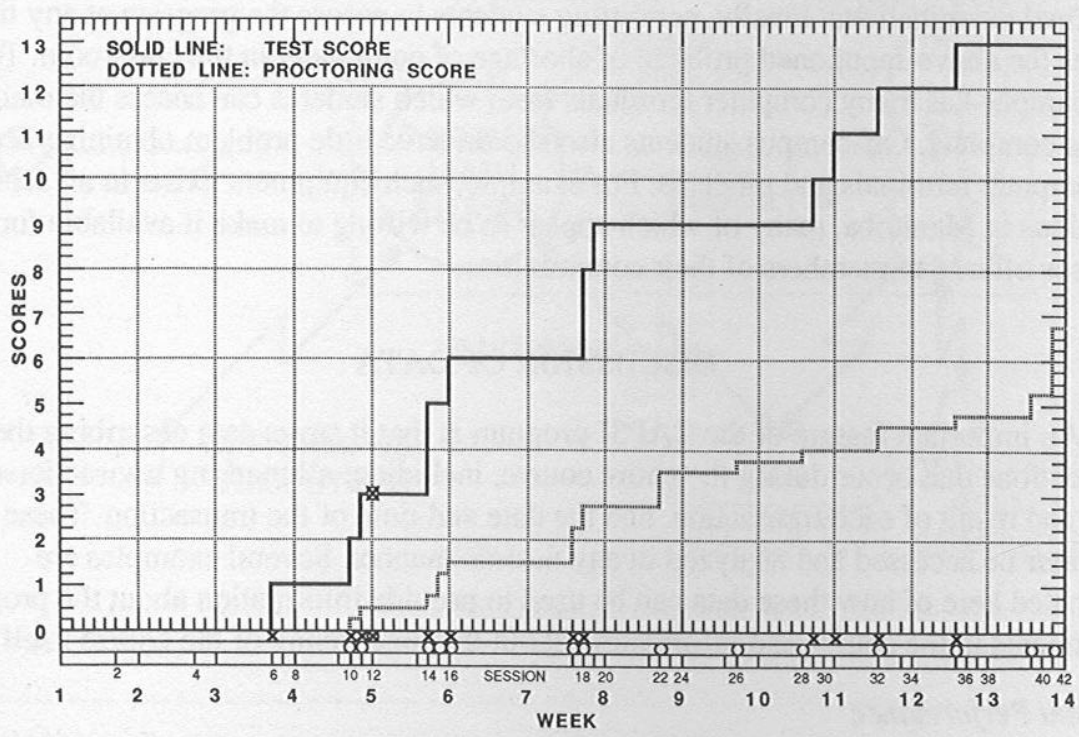


FIGURE 3c. Examples of Test and Proctoring Scores (solid line: test score; dotted line: proctoring score). Student C. Total Test Score $=13$; Total Proctoring Score $=0.00$.

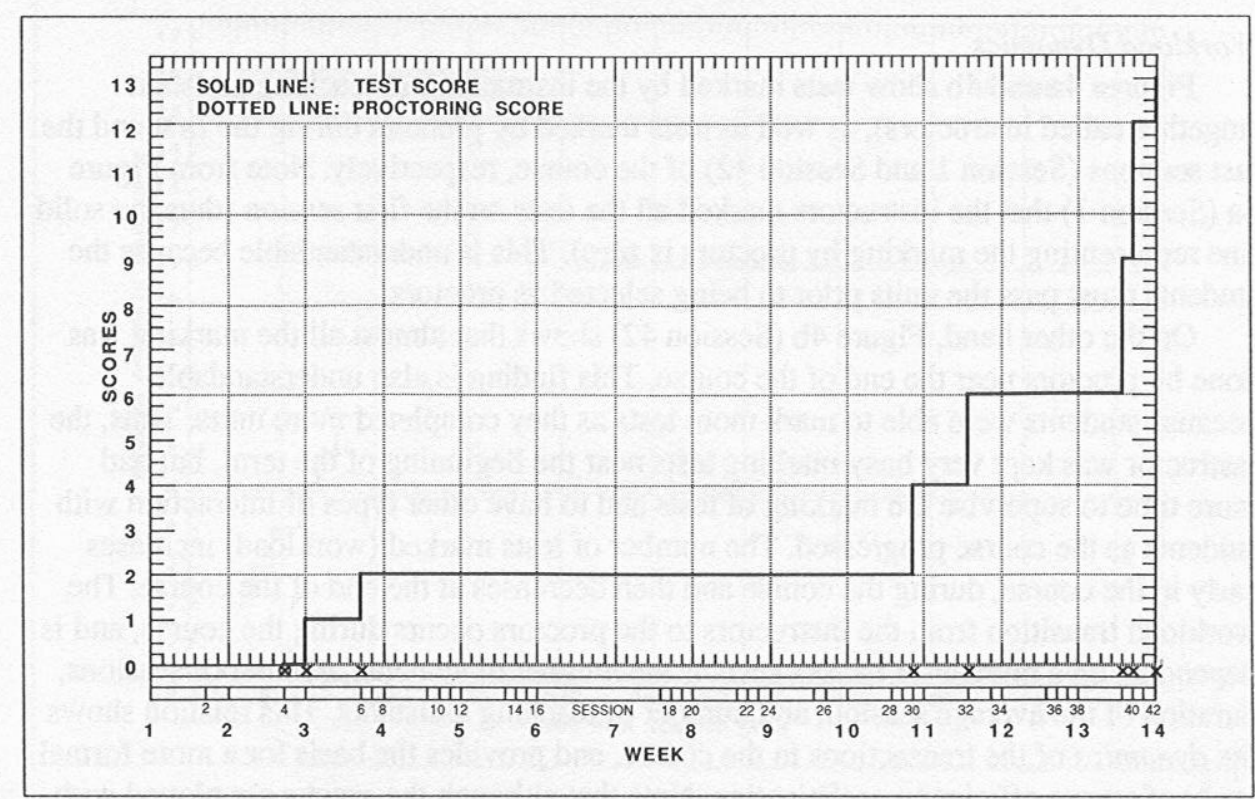

respectively, in a second-term on-campus "Behavior Modification Applications" course (Course 1) from the beginning of the course on 8 January 1987 to its closing date of 9 April 1987. Test scores on units completed and proctor scores are plotted against the time of the course. The course had a total of 13 units, and 0.25 point was received by a proctor for each test marked. In the three rows under each graph, successful test attempts are indicated by crosses, while each unsuccessful test attempt by a cross in a circle; proctoring interactions are indicated by circles; and dates on which class sessions were held are indicated by the vertical ticks. Session numbers are also place under the graph.

Note from Figure 3a that Student A started the course during Session 1 (8 January), passed units at a high rate, and completed the units during Session 20 (26 February), before the middle of the course. As shown in Figure 3b, Student B started three weeks later, progressed through the course at a slower pace, and completed the units during Session 41 (8 April). Despite progressing through the units at a lower rate, Student B earned more proctor points as a result of serving as a proctor over a larger number of sessions (6.75 against 4.75 of Student A), while Student A probably stopped attending class after completing the units, and therefore did not serve as a proctor after that date. Also note that Student B unsuccessfully attempted a test during Session 12. As shown in Figure 3c, Student C started two weeks later, completed the first few units fairly early in the term, and then did no further work until about three weeks before the end of the term. This student then passed unit tests at a very high rate and managed to complete all the units by the last day of class. However, the student did not earn any 
proctor points in the course, which was probably due in part to insufficient time to mark tests during the last three weeks. Also note that Student $\mathrm{C}$ unsuccessfully attempted a test during Session 4.

\section{Workload Dynamics}

Figures $4 \mathrm{a}$ and $4 \mathrm{~b}$ show tests marked by the instructor and teaching assistant (together called instructors), as well as tests marked by proctors during the first and the last sessions (Session 1 and Session 42) of the course, respectively. Note from Figure 4a (Session 1) that the instructors marked all the tests on the first session (thus the solid line representing the marking by proctors is zero). This is understandable because the students must pass the units prior to being selected as proctors.

On the other hand, Figure $4 \mathrm{~b}$ (Session 42) shows that almost all the marking was done by proctors near the end of the course. This finding is also understandable because students were able to mark more tests as they completed more units. Thus, the instructor was kept very busy marking tests near the beginning of the term, but had more time to supervise the marking of tests and to have other types of interaction with students as the course progressed. The number of tests marked (workload) increases early in the course, during the course and then decreases at the end of the course. The workload transition from the instructors to the proctors occurs during the course, and is dependent on a number of factors such as the number of students, number of sessions, duration of the average session, and number of teaching assistants. This relation shows the dynamics of the transactions in the course, and provides the basis for a more formal study of course efficiency optimization. Note that although the graphs are plotted with resolution of one minute, CAPS1 time is recorded to a second.

\section{Analysis of Student Evaluation Process}

For two different courses (Behavior Modification Applications [Course 1] and Humanistic and Transpersonal Psychology [Course 21). Figures 5a and 5b present the following data: a) the number and percentage of times students cancelled their tests, b) the number and percentages of passes, c) conditional passes (where students are permitted to correct a minor error), and d) restudy - all issued by the instructor or teaching assistant (left bars) and by proctors (right bars).

One point that is clear from these data for both courses is that considerably more tests were marked by students than by the instructor or teaching assistant, while proportionately fewer restudy results were given by proctors than were given by the instructors. This could be taken to indicate that the instructor and teaching assistant marked more strictly than did proctors; however, this conclusion may not be warranted because it does not take into account the fact that the instructor and teaching assistant did more marking early in the course, before. students had adjusted to the stringent requirements of the course. It is also interesting to note that students cancelled tests more times than they were given restudy results by all markers combined. This indicates that students realized when they had not performed adequately on a test and did not submit it for marking when a restudy result was likely to be the outcome.

With the modified CAPS1 in which students are permitted to access the program whenever they wish and to send the test answers by electronic mail, another type of 
FIGURE 4a. Examples of Tests Marked by Proctors (solid line) and Instructors (dotted line). Session 1. (Note: No test was marked by proctors.)

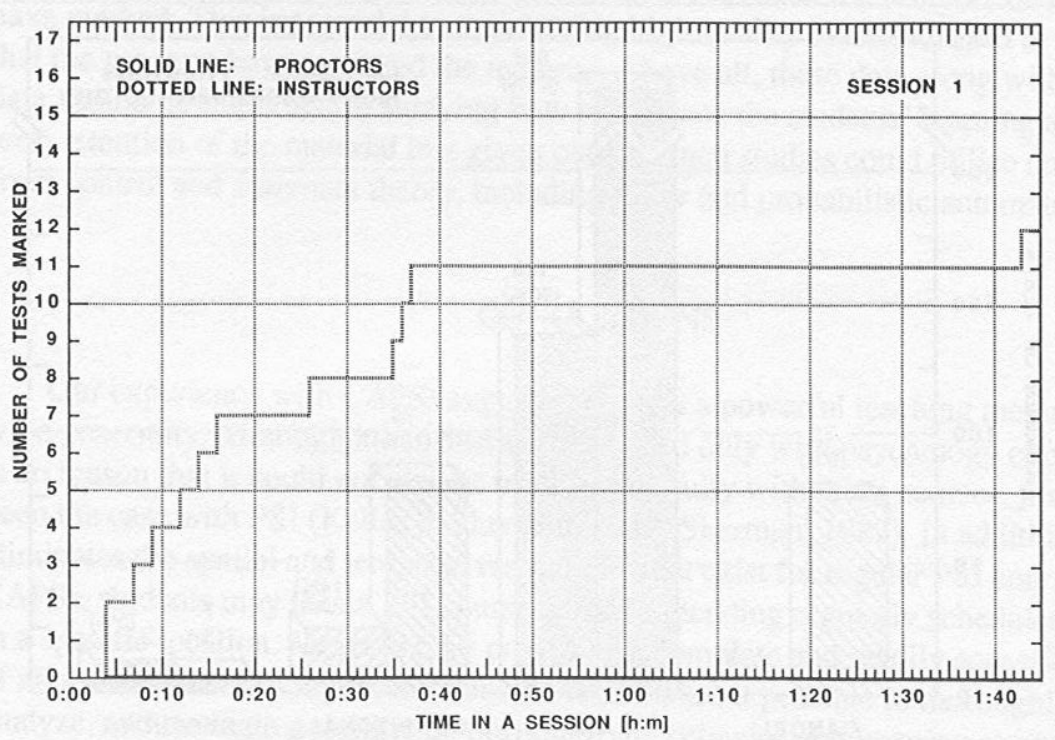

FIGURE 4b. Examples of Tests Marked by Proctors (solid line) and Instructors (dotted line). Session 42. (Note: Only one test was marked by instructors.)

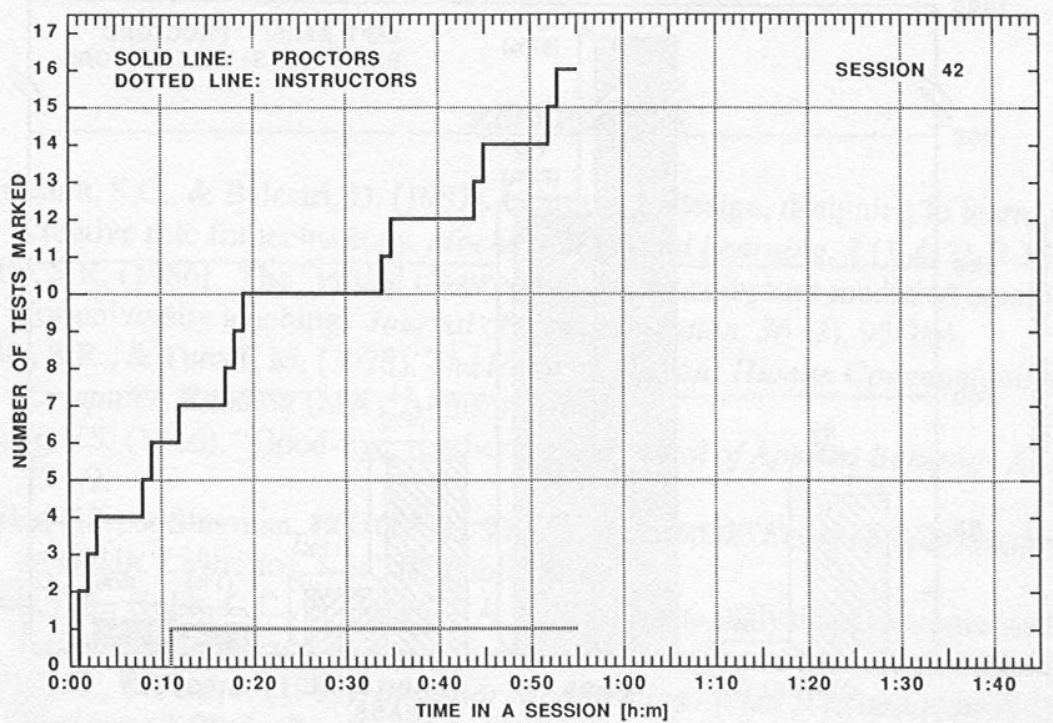


FIGURE 5a. Marking of Tests (Left Bars: Proctors; Right Bars: Instructors and Teaching Assistants). Course 1. Total Number of Tests Attempted =990; Marked by Proctors = 749; Marked by Instructors = 169; Cancelled $=72$.

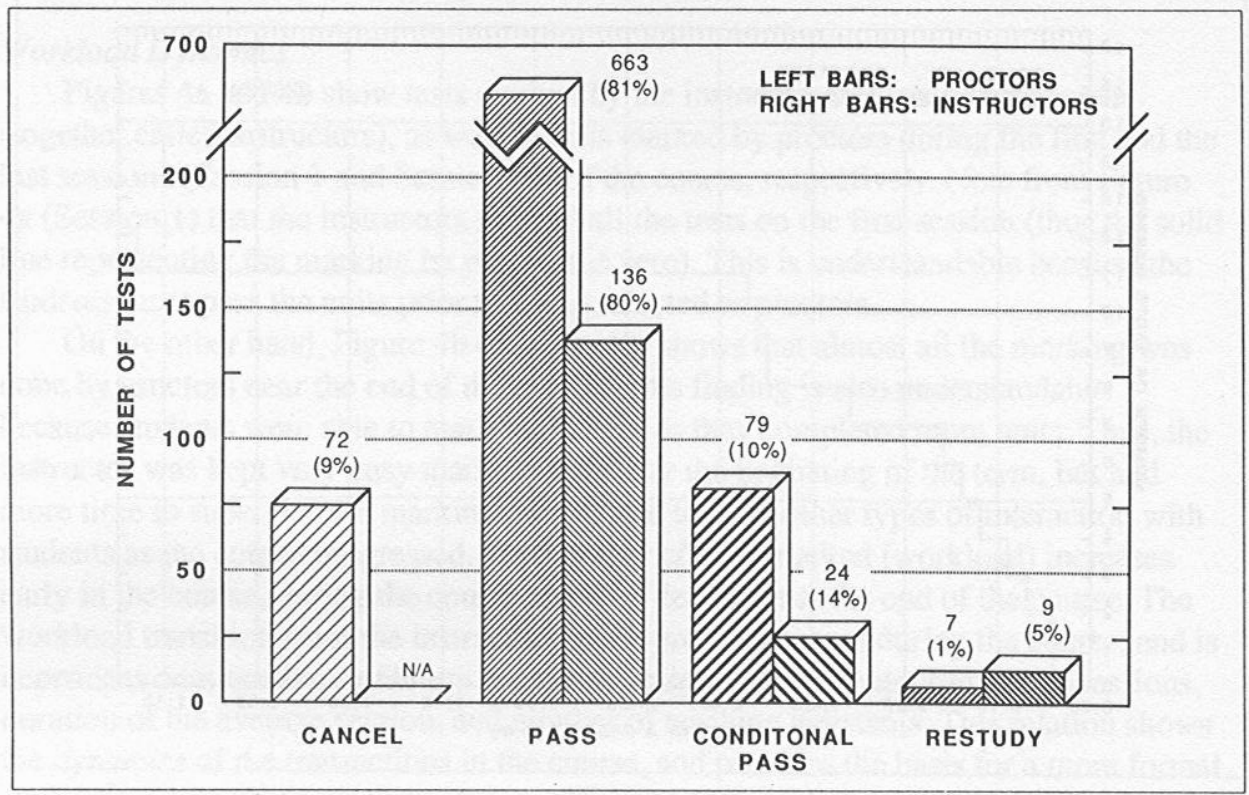

FIGURE 5b. Marking of Tests (Left Bars: Proctors; Right Bars: Instructors and Teaching Assistants). Course 2. Total Number of Tests Attempted = 1332; Marked by Proctors = 1118; Marked by Instructors $=208 ;$ Cancelled $=69$.

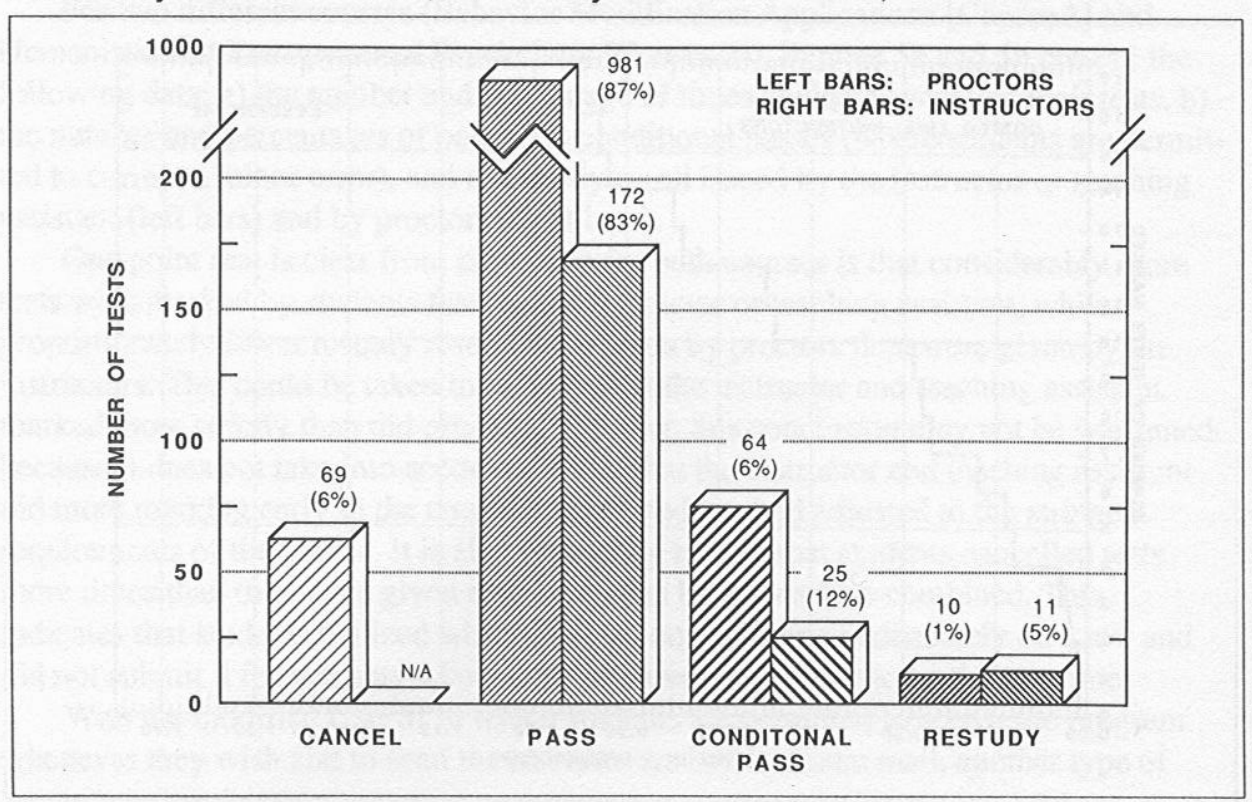


data is being collected. All tests and the feedback given to students by the proctors are stored in a dataset that the instructor can access. The instructor can thus periodically scan these tests for marking errors, and provide feedback to the proctors on tests they have marked. This is essential in maintaining high-quality evaluation and in ensuring that the proctors have mastered the material. Above all, these data along with the other data should be important in studying how to enhance the students' learning and longterm retention of the material in a given course. Such studies could utilize concepts from control and automata theory, including fuzzy and probabilistic automata.

\section{CONCLUSIONS}

Our experience with CAPSI suggests that it is a powerful teaching method with wide generality. Although it has thus far been used only with psychology courses, there is no reason that it could not also be used successfully with other courses, just as has been the case with PSI (Keller \& Sherman, 1982; Sherman, 1982). In addition, CAPSI eliminates the spatial and temporal restrictions that exist for regular PSI courses-with CAPSI, students may take a PSI course without attending regularly scheduled classes in a specific location. Moreover, by providing a complete and readily accessible record of all testing and marking interactions, CAPSI makes it possible to thoroughly monitor, analyze, and evaluate a significant portion of the behavior and learning engendered in the course. This should be useful in learning how to improve the educational process, including the instructional presentation and upgrading of the objectives. Finally, CAPSI opens a door leading to the next stage of computer-aided instruction, in which the computer will become more intimately involved in the educational process by aiding in the development of course materials and in the evaluation of the student's learning.

\section{REFERENCES}

Ehrmann, S.C., \& Balestri, D. (1987). Learning to design, designing to learn: A more creative role for technology. Machine-Mediated Learning. 2 (1 \& 2), 9-33.

Hiltz, S.R. (1986). The "virtual classroom": Using computer-mediated communication for university teaching. Journal of Communication, 36 (2), 95-104.

Hiltz, S.R., \& Turoff, M. (1978). The Network Nation: Human Communication via Computer. Reading (MA): Addison-Wesley.

Keller, ES. (1966). "Good-bye, teacher . . . ." Journal of Applied Behavior Analysis, 1, 79-89.

Keller, ES., \& Sherman, J.G. (1982). The PSI handbook: Essays on personalized instruction. Lawrence, KS: TRI Publications.

Kulik, J.A., Kulik, CC., \& Cohen, PA. (1979). Meta-analysis of outcome studies of Keller's personalized system of instruction. American Psychologist, 34, 307-318.

Martin, G., \& Pear, J. (1983). Behavior Modification: What It Is and How to Do It. Englewood Cliffs: Prentice-Hall, (2nd edition). 


\section{CJEC WINTER 1988}

Montgomerie, T. Craig (1987). Facilitating 'Extended Campus' graduate education through electronic communication. Canadian Journal of Educational Communication, 16 (3), 205-216.

NATAL-II -A National Authoring Language. (198 1). Honeywell Information Systems and National Research Council.

Pear, J.J., \& Kinsner, W. (in press). Computer-Aided Personalized System of Instruction: An effective and economical method for short- and long-distance education. Machine-Mediated Learning.

Robertson, W. (1986). Use of audio teleconferencing. In I. Migridge \& D. Kaufman (Eds.), Distance Education in Canada (p. 283-295). London: Croom Helm.

Sherman, J.G. (1982). PSI today. In J.G. Sherman, R.S. Ruskin, \& G.B. Semb (Eds.), The personalized system of instruction: 48 seminal papers (p. 346-352). Lawrence, KS: TRI Publications.

Sherman, J.G., Ruskin, R.S., \& Semb, G.B. (Eds.) (1982) The personalized system of instruction: 48 seminal papers. Lawrence (KS): TRI Publications.

Skinner, B.F. (1953). Science and human behavior. New York, NY: The Macmillan Company.

Skinner, B.F. (1954). The science of learning and the art of teaching. Harvard Educational Review, 24, 86-97.

Skinner, B.F. (1961). Teaching machines. Scientific American, 205, 90-102.

Woolf, B.P. (1987). Representing complex knowledge in an intelligent machine tutor. Computational Intelligence. 3,45-55. 


\title{
Computerized Television: Technology Overshadows Aesthetics
}

\section{Nikos Metallinos}

\begin{abstract}
Such rapid developments in telecommunication technology as computerized television recording, television editing, television graphics, laser video discs, etc., have revolutionized the structural processes of television images. New television production techniques have been generated which, in turn, make new approaches to the study of television production techniques and television aesthetics a necessity. But is new always better? In this paper, various technological and artistic developments in the area of television production are examined via their potential effects on viewers' comprehension and appreciation of televised programs. It is suggested that rapid technological developments in television production hardware will continue being made in spite of the dubious educational value of such technologies. Effectiveness in educational communication does not always keep pace with the speed at which these techniques are adopted. Consequently, neither television production techniques, nor the study of television aesthetics will benefit iftheviewer isnotgiventhechancetoperceiveandfullyappreciatethetelevised messages.
\end{abstract}

Scholarswhohaveobservedtheinfluenceofcommunicationtechnologyon contemporary society have long ago identifiedours as the information society. New communication media technologies havecaused an information explosion in contemporarysociety whichhasreachedglobaldimensions(Arnopoulos, 1982;Valaskakis, 1980; Rogers, 1986). As isthecase with such explosions, however, the entire environment has been shaken up, altered, or even damaged and many observers are concerned and alarmed about it (McPhail, 1986).

In the field of visual communication in general (the academic discipline which studies the processes and the effects of thevisual communication media), and in educationaltelevisionproduction techniquesinparticular,observershavewarned us that some ecological changes and environmental damage due to many new technological advances in television production techniques can be devastating (Zettl, 1982). Many viewers are fascinated by and attracted to the new visual imagery but remain unaware

Nikos Metallinos is an Associate Professor in the Department of Communication Studies at Concordia University, 7141 Sherbrooke Street W., Montreal, PQ H4B 1 R6. His interests are in the area of visual communication, media research, television production, and television aesthetics/criticism. 
of and often indifferent to the visual content and the synthesis of such peculiar visual messages (Chartrand, 1986). In other words, television viewers see the changes in television production techniques as they appear on the television screen, but are unaware of the potential covert effects such visual displays might have on them. Furthermore, the new computerized television pictures may be able to catch viewers' attention and curiosity instantly, but constant exposure to such images can immunize viewers' perceptual and cognitive ability (Treisman, 1986) to such an extent that recall of these visuals is found to be minimal (Metallinos, 1985; White, 1986).

How are we, in the field of educational communication media, to warn viewers of the possible effects of these technological advances in television production imagery? Are there workable ways to inform viewers of these gimmicks and to prepare them to choose visual comprehension over visual confusion? Scholars in the fields of visual communication, perceptual psychology, television composition, media criticism, and educational communication have all provided some answers. They have all helped to establish the interdisciplinary communication field known as television aesthetics which examines such basic elements of television production as light, space, time, motion, and sound in relation to each other, and to the total television program. If viewers are aware of the aesthetic value, the educational ability, and the communicative potential of given television images, it is thought that they will become more selective in their choices of television programs. Research studies in television aesthetics, some scholars suggest, will enlighten the viewers and allow them to exercise effective and workable value judgements underlined in such television aesthetic research studies (Zettl, 1982; Baggaley et al., 1980; Coldevin, 1981). Viewers and critics alike, aware of these guidelines, will be able to point out the visual gimmicks of computerized television, and thus to avoid them.

Concerned about the abuse of these new technologies introduced in television hardware, Zettl(1982) questions the intentions of these technologies via the effects they might have on contemporary television viewers. He asks:

\begin{abstract}
A whole new level of pictorial abstraction has evolved in television presentations with new production requirements and I am sure, with new perceptual effects on the viewer. But what exactly are they? Do such animated graphics maximizecommunication? What is the full potential of such visuals? Whatare their covert effects on our perception? Are they ecologically sound or do they, or could they, add to the pollution of our electronic environment?
\end{abstract}

In this paper, a series of new developments in television production technologies will be examined via their influence on the aesthetic quality of the television program. A key question addressing the problem of media technology versus media aesthetics is: do new developments in television production techniques increase viewers' awareness, comprehension, and appreciation of the entire content of the end product, the television

For an analytical and comprehensive examination of this question, the following three subquestions emerge to guide the study: a) Due to the overall technological developments in telecommunication media during the last decade, which particular units of the television system have been drastically changed? b) In what specific areas 
and to what degree have changes in television production hardware covertly influenced television viewers? and c) What is called for in the future concerning the composition of television images and their presentation?

\section{DEVELOPMENTS IN TELEVISION EQUIPMENT}

A sizeable number of new telecommunication media have emerged during the last decade such as cable television, direct broadcast satellites, video games, video texts, teletexts, two-way television, computer graphics, holography, etc. (Fletcher, 1984). As a consequence of these developments, a considerable number of technologies have emerged in television hardware which have had a profound effect on the end product. In this section, the most important such developments will be examined via their influence on the synthesis of television pictures.

\section{Cameras}

The television camera, which is the first unit in the television production system, has undergone drastic changes over the last decade. From the RCA TK-60 monochrome big TV studio camera to the portable, solid state, digitally controlled models, cameras have been greatly improved. They provide maximum picture clarity and require less lighting (e.g., the small ENG/EFP camera); they offer maximum depth of field (e.g., the big TV studio cameras such as the RCA TK-4 and other similar ones). Equipped with higher quality electronically operated zoom lenses and supported by new, lighter, and more flexible camera apparatuses (such as pneumatic studio pedestals, TV studio cranes, etc.), the big studio cameras have enhanced the quality of TV studio productions. Unstable and often unnatural camera movements of the past such as dollying, pedestalling, panning, trucking, etc., have been replaced by more stable, smoother, and more flexible camera movements which convince the viewers that they are directly observing the action. Equally, the development of smaller, portable television cameras has changed both traditional television production processes (i.e., news, sports, rock videos, documentaries, public affairs events, etc.) and television production techniques (i.e., live, direct broadcasting which bypasses editing). Network competition in news gathering has triggered the development of new technology and generated ENG/EFP (Electronic News Gathering/Electronic Field Production) procedures. These procedures, in turn, have revolutionized television production techniques, challenging the human involvement, the software, of television production.

Several improvements in television production videotaping techniques were made due to the invention of the high-flying computer guided cameras known as skycam, and the hand-held cameras known as steadycam. Skycam has helped to substantially modify sportscasting techniques (Talen, 1986), and the steadycam has brought the media of film and television closer together. As television cameras have become smaller and more flexible, they have come to be handled as film cameras, merging film with video to create the field of electronic cinematography, one of the major revolutions in television production techniques and television programming today. In Mathias' and Patterson's (1985, p.xii) view, "Electronic cinematography is a new form 
of production, born of the marriage of video hardware and film techniques; it offers not only the best of both worlds but entirely new creative possibilities."

Such creative possibilities have been in practice since the introduction of the first broadcast quality ENG/CCD (Charged Couple Device), the solid state technology attached to small video cameras. These cameras, according to Westport (1984), create video pictures that capture almost everything a film camera captures.

Similar creative possibilities also emerged with the introduction of HDTV (High Definition Television) cameras by Sony in Japan and Philips in Europe. Using a double PAL Signal, these cameras produce pictures of as high a quality as those of film cameras. According to Schubin (1978, p.77), "HDTV can provide details as crisp as those in $35 \mathrm{~mm}$ film and will enable filmmakers to begin to take advantage of all the beneficial aspects of video technology." Mathias and Patterson (1985) project that "the future demands a new analysis of the visual techniques that will be required by the improved picture quality of HDTV and its application to dramatic subjects."

Lights

Improvements in television lighting equipment, brought about mainly to meet the electronic demands of the new television cameras, have occurred in several major areas.

First, the lighting instruments themselves have improved. The heavy, bulky, old incandescent lighting instruments used in film studios such as Fresnels and scoops have been replaced with smaller, more flexible, easily manageable lighting instruments. These lighting instruments use quartz (tungsten-halogen) lamps, or H.M.I. (HalogenMetal-Iodide) lamps. This change allows for faster lighting set-ups and the use of less lighting instruments. Another important development occurred in the area of portable lighting instruments with multiple usage. New television lighting instruments were developed which can be used either in complex television studio productions, or in remote, or location shooting. Instruments such as the Sweep Focus or External Reflector Lights (Zettl, 1984), the Ring Focus Fresnel Spotlights (Zettl, 1984), and the OmniLight (Lowel) for the ENG/EFP cameras (Zettl, 1984) are specialized instruments and their multiple use capabilities have increased the creativity of lighting engineers.

An additional development has occurred in the area of lighting controls and intensity controls through dimmers. The previous manual dimmer control consoles in which each light intensity had to be controlled by hand, have been replaced by new, often computer assisted dimmer controls. This development allows the television production crew 1) to control the intensity of the light at will, 2) to change the lighting from one set to another more quickly, 3) to change the colour of a scene, 4) to create special effects such as night light, sunsets, etc. (Zettl, 1984), and 5) to set up the lighting for several scenes at a time, economizing production time. In planning television lighting equipment, contemporary television production centers emphasize the need to produce multiple productions with an improved look, with a rationalized production flow, with limited production time, and which permit alterations at any time" (Kreckel, 1985, p.46).

Audio

The entire technology of television's audio equipment such as microphones, audio 
recording units, audio consoles, stereophonic sound, etc., has been updated and refined, improving the quality of television sound substantially. Television production no longer uses conventional microphones used in film productions. It has created its own dynamic condenser ribbon-type microphones which operate both as mobile and as stationary microphones. They range from boom, hand, lavahere, and wireless, to desk, stand, hanging, and hidden microphones. The quality of sound and the pick-up range produced by these microphones is superb, and their production flexibility and usage has greatly increased. In the area of sound recording units such as turntables, tape recorders, audiotape cartridges, reel-to-reel tape recorders, etc., great improvements have occurred providing excellent service and flexibility for the recording of television programs.

Audio control equipment of television systems has undergone the greatest change. The traditional manual audio consoles (such as RCA's BC-7), commonly used in television studio operations in the past, have been replaced by new, multi-channel, stereo, computer assisted audio consoles. Working with slide factors (such as the Audio Design BC-5), these new consoles are capable of storing and controlling many audio inputs, and are able to synthesize and produce a of sounds and sound effects which were previously impossible to achieve (Zettl, 1976).

Finally, the most revolutionary change in the audio unity of the television system has occurred with the introduction of stereophonic sound for television (Kaller, 1986). This innovation has elevated audio quality to a higher level than video quality. Those who have attached an FM band to their television sets can attest to such a serious imbalance. The presently low definition television picture is aesthetically incompatible with the high quality of stereophonic sound (Zettl, 1982). When, however, stereophonic television and HDTV are allowed in North American broadcasting, this discrepancy will be resolved.

\section{Special Effects}

The television production unit known as the switcher or special effects apparatus has also undergone revolutionary changes and improvements. The switchers of the past had the capabilities to fade in and out, dissolve, cut, superimpose, chromakey, matte, matte key, clip, debeam, wipe, feedback, spot, etc. (Zettl, 1976). Today, the development of new computer enhanced DVE (Digital Video Effects) switchers allows such additional effects as flip-flops, quad split controls, cascading, double re-entries, screen simulations, multi-images, mirror or echo effects, compression and expansion, horizontal and vertical flips, autokeytracking, perspectives, posteriorization, mosaics, size and position changes, zoom effects, slide effects, rotation effects, fix effects, cube rotation effects, etc. (Zettl, 1984).

The consequences of these developments to the study of television aesthetics are numerous. Circumstances and scenes which are totally impossible in real life can be recorded and produced visually through the magic of the television switcher. Beyond a shadow of a doubt, the visual effects produced by the DVE attached to the computer assisted switchers are fascinating and attractive. They draw the viewers' attention and trigger their imagination. They provide easy solutions to complex production processes making the impossible appear possible. In short, they are used as attention stimulators 


\section{CJEC WINTER 1988}

and entertaining devices. But should this happen so freely? Does this visual pandemonium enhance the content of the programs which make use of them? Are they always ethical in their intentions or justified in their purposes? Visual communications media observers fear that over-emphasis of visual gimmicks diminishes the credibility of the medium as an art form (Zettl, 1982), and constant exposure to such visual barrages can have covert effects on viewers' comprehension and appreciation of the content of such televised programs (Metallinos, 1986).

\section{Recorders and Editors}

There has been steady development in television production recorders and editors during the last decade. Since 1976 when Ampex introduced the VPR- 1, the first helical scan videotape recorder and its portable model the VPR-10, video recording has greatly improved. Recording machinery, modified and improved, has formed the basis for video editing technology. Starting with single source editing and precise electronic equipment, television editing has reached a high degree of sophistication. It is known that $85 \%$ of today's televised programs are the outcome of post-production or heavy editing. As a consequence, the production process (capturing original images in the studio or in the field) has been minimized and the sophistication of television editing machinery has been greatly elevated. An account of the post-production equipment which furnishes most of television production centers is given by Paulson (1984) as follows:

\footnotetext{
The average post production suite is outfitted with three or four editing videotape machines; a film to tape transfer unit; a switcher with two or more preprogrammable mix/effect buses controlling 10 to 20 input sources including single or multi-channel character generator, and a small computer-based videotape machine and switcher controller capable of executing long lists of preprogrammed mixing and edit decisions. The latest update of this basic configuration is a suite that adds computer control of multi-channel audio switcher.
}

This shift from studio or field based creation, in which human beings were heavily involved, to an assemblance of synthetic images made by machines, could have consequences as yet unforseen.

\section{Video Screens}

Although the standard 3:4 aspect ratio television screen is still the most commonly used around the world, the development of the large screen in 1973 with its 3:5 aspect ratio has helped to modify the television production approach. The first big television screen named Videobeam was "... a a three colour-tube projection system with a special six-by-four-foot screen that produced a bright picture more than ten times larger than that of the biggest conventional TV set. . ." (Lang, 1976, p.24). Then as HDTV was developed and the standard television screen's picture was improved, Big Video Screens were developed in Japan. Describing one such Big Video Screen on his visit to Japan's Tsukuba Expo ‘85, Costello (1985, p.28) states: 


\begin{abstract}
When the huge screen is turned on, loudspeakers announce that it's "zoom-in time." A camera picks out people or groups gathered on the grass near the 82foot-high and 131-foot-wide Jumbotron, which is the world's largest TV and video display screen. With an aspectratio of five to three, Jumbotron can receive HDTV pictures as well as the standard NTSC. The screen is 10,000 times the size of a 20 -inch TV screen and 30 times brighter.
\end{abstract}

The Big Video Screens, although still in limited use, will influence television production techniques. The traditional videotaping techniques developed for small screens cannot be employed successfully with large screens.

\title{
3-D, CATV, DBS
}

Although technological developments have occurred in every type of hardware in the television system, and it is impossible to single them all out, 3-D video, Cable Television (CATV), and the Direct Satellite Broadcast System (DBS) deserve some attention.

The technology of 3-D television is not new. It has grown alongside the cinemascope concept and has always had problems. However, the creators of the system believe that 3-D will flourish again and offer exciting visual possibilities for the near future. As Green (1983, p. 29) states:

Before its recent revitalization, 3-D was viewed as a gimmick that had the faddish future of shaky speculation. Now however, with its feet on firm ground, and with the marketing support it deserves, 3-D productions, particularly in the field of 3-D video broadcasts, can look forward to an exciting development of its perhaps yet undreamed of possibilities.

Computerized television switchers and digital video effects attachments are producing three dimensional types of pictures on the small television screen which have superb quality.

The technology of cable television is not limited to transition of video programs. As a distribution system, disseminating information through ground wire, cable television has contributed to the development of television production. It has taken the time to produce new and more challenging television programs and offers the opportunity for more artistic expression in its production process than networks do.

The technology of Satellite Broadcast Communication is new and fast developing. As a geospheric distribution system, it offers great possibilities in the development of new television programming which, in turn, will require a different approach to television production techniques since there must be precision and universality in programs which will be seen globally.

In summary, the technological developments in the hardware of the television production system are directly affecting television production techniques, and consequently, the form of televised programs. Improvements in technology are producing better quality (technically) television pictures and sounds. But the question still remains: What particular covert effects will such technological developments have on those who work with them and viewers who consume the products of television? 


\section{IS NEW ALWAYS BETTER?}

Although television is the most widely used medium today and one of the most effective communication media the world has ever known, the influence of its programming on viewers is not always immediate or apparent. Researchers on the influence of television programming on society (Gerbner, Cross, \& Melody, 1973; Wright, 1959) contend that the cultural influence of television on special groups takes years to show up. During that time, the socialization process takes place and several cultural indicators arise which help us to identify the degree to which television has influenced specific viewers.

These cultural indicators often show us where we went wrong and point out the areas we need to correct. Usually it is too late to make any changes since the viewers have already been conditioned to accept certain visual stimuli, regardless of their compositional or aesthetic merits. It is for this reason that media technology ought not to surpass research in media related factors. In this section, the covert effects that new television production technology have had, or could have on contemporary viewers, will be pointed out. Examples will be drawn from such popular and common television programs as newscasts, sportscasts, magazine type programs, and music videos. The production factors explored will be limited to: a) Cameras and Lenses; b) Special Effects and Computer Graphics; and c) Screen Composition and Setting.

Changes in the content of news programs have not occurred over the last ten years. But the medium's treatment of the presentation of the news has changed. By and large, the network news has been polished, field or on-the-scene reports have increased, visuals have also increased (most of the visuals appear like the pages of popular news journals). The news has taken on a journalistic appearance. The various parts of the television screen are filled in with other images and visuals in addition to the anchorperson. Some of these visuals are frozen (digitally), others have lettering, while yet others use live action squeezed in on each of the four comers of the television picture. Regardless of what researchers in educational communication, visual media, and communication studies have suggested about the production and presentation of television news (Coldevin, 1978a, 1978b; Bernard \& Coldevin, 1985; Baggaley, 1974; Metallinos, 1977), commercial television producers allow technology to overshadow research.

Changes in the format of Sportscasts are quite evident to all sports fans. Using skycam cameras, slow motions, instant play backs (from different angles), special effects, etc., sportscasts television programs have managed to recreate the sports events. What we see on the television screen is not a complete picture of what is happening on the field. It is a new event, hardly realistic, often exaggerated, and always glamorized.

The magazine type television programs such as 60 Minutes, 20/20, Good Morning America, and the successful nightly program Entertainment Tonight, in particular, are striking examples of 'speedy gossip journalism' presented glamorously through digital television images.

Music videos for the most part have pushed television imagery to its extremes. Distorted lenses, tilted horizons, unpredicted cuts and zooms, unusual fast paces, and unsuspected digital video effects create a visual collage which is often incomprehensible, incohesive, and indistinguishable to children and usually annoying to adults. 


\section{Cameras and Lenses}

Most network newscasts commonly use the small ENG/EPP cameras which are linked directly with the station and provide visual and verbal information. But the rush to be first with the news on the air usually produces field footage poorly shot, scenes which are unevenly lit, framing which is totally imbalanced, and sounds which are undesirable noises of the environment. Such poor presentations are common practice in network television newscast productions. We experience an improvement in television camera technology (hardware), yet we are badly lacking the educational and aesthetic benefits (software) of such technology. As Coldevin (1981) and Zettl(1982) point out, we have advanced technologically but are decisively behind in research studies and experimentation with it.

Do we really believe that television viewers are not affected by gimmicky camera shots or unsteady camera movements? The technology of video lenses has offered a great service to television production due to their flexibility and optical range. But the lenses have not always been used aesthetically. An example of over-stretching the power of the telephoto super zoom lenses is shown in many rock videos in which the lenses are used freely. The compositional value of such video recordings leaves a lot to be desired. Many rock videos often overlook and defy basic principles of aesthetic composition. Distorted faces, tilted horizons, fast motions all created by unorthodox zoom lens usages are not always justified. Even the younger viewers for whom rock videos are made are becoming less and less fascinated with extensive visual gimmicks. As limited as research in television cameras and lens related factors might be (Coldevin, 1981; Metallinos, 1985), there is still enough evidence to support that such undesirable camera movements and camera shots do affect the viewers' comprehension and appreciation of hastily produced television images (Wurtzel \& Dominick, 197 1-72; Baggaley, Ferguson, \& Brooks, 1980; McCain \& Divers, 1973; McDaniel, 1974).

\section{Special Effects and Computer Graphics}

Another common technology which is widely used, primarily in newscasts and sportscasts but also in rock videos and magazine shows, is special effects and particularly DVE. To enhance the content of the programming and for the purpose of attracting the viewer's attention, the technology of television Special Effects is used to rescue the show. The extensive use of DVE's flipping and flopping of faces (i.e., the evening network television program Entertainment Tonight), compression or expansion of landscapes, the fast changes in size and position of visuals, and a barrage of other such visual tricks are often confusing and redundant. The aesthetic value of the visuals is dubious and serious observers of the medium have questioned the use of such special effects. Zettl (1986), for example, raises the questions:

Does such visual treatment enhance the news and make it more important? Or is it a gimmick, prompted by the manufacturers of DVE (Digital Video Effects) equipment who invented such devices oblivious of use, and who now like to sell their goods and find some satisfaction and justification in seeing their technical creations applied, however frivolously?

The perpetual use of such digital video effects (DVE) coupled with fast zooms in and out, have been found to have profound, covert effects on children (Tiemens 
Acker, 1981; Coumuntzis, 1987; Calvert, Huston, Watkins \& Wright, 1982; Gzesh \& Surber, 1985). Certainly the unnatural or unrealistic ways by which the objects (trees, houses, cars, landscapes) of the visual world appear on the visual field, the television screen, make children wonder about the environment. What is, then, the educational value or the aesthetic merit of the DVE if they are usually incomprehensible for children, and incohesive for adults?

Extensive use of computer-generated graphics has created a new phenomenon in the television production of daily news and interview shows called graphication of television news. Zettl(1986, p. 2) defines this as "ah aesthetic devices that are used to make a television image two-dimensional or graphic-like, often similar to a magazine page." This aesthetic device imitates the older, more traditional medium of print. These visual gimmicks may, momentarily, attract the viewers' attention. However, empirical evidence suggests that they do not enhance the viewers' comprehension of the content of the news items. Zettl(1986) challenges these kinds of practices stating that:

\begin{abstract}
Computer-generated graphics pop on the screen to give us headlines, field reporters and their stories are squeezoomed in and out over the news anchor's shoulder, and fancy lettering repeats what we have heard the newscaster tell us. Through the magic of digital video, live scenes are frozen into still images and peeled off page by page as though we were flipping through a magazine.
\end{abstract}

Schubin (1986, p.68), a regular columnist for Videography magazine, calls such effects "cheap thrill." Technical production variables, such as special effects and computerized graphics, could be educationally useful and aesthetically valuable when they are purposefully and sensibly incorporated into televised images.

\title{
Screen Composition and Setting
}

Screen composition and setting are additional production factors overstressed and abused by the modem technology of digital television imagery. Screen composition refers to the appropriate arrangement of all visual elements within the concentrated space of the television screen. An appropriate arrangement of all visual elements is possible when the compositional principles of direction, proportion, and balance are employed. Furthermore, appropriate screen composition is potentially achieved when certain internal factors related to the television picture are taken into consideration by the television picture creator. Such factors as magnetism of the frame, attraction of mass, asymmetry of the screen, figure\&round relationships, psychological closure/ Gestalt, and vectors (Metallinos, 1979), are scarcely considered by contemporary television picture constructors who make extensive use of technology in view of aesthetics. For example, the comprehension and recall of visuals placed on the Z-axis is minimal when visuals move in and out over a certain speed limit (Chartrand, 1986).

Studies on the stability and constancy in visual perception indicate that the average observer of visual stimuli requires certain visual conditions and needs a certain amount of time to successfully perceive and accurately recognize the motion of visual materials (Epstein, 1977). The instability and inconsistency presented to the viewer by distortion of visuals and fast moving objects along the Z-axis is commonly observed in televised rock videos today. However, are network television producers sensitive to the covert effects of these gimmicks? Studies dealing with the complexity of television messages 
and the degree of attention paid to them by the average viewer reveal that the more visually complex the television message, the more mental effort is required by the viewer to comprehend it (Thomson, Reeves, \& Schleuder, 1985).

Most visually complex television programs do not allow for the extra mental effort required (White, 1986). Neither the composition, nor the setting, are being perceived or understood since both are complex and move with great speed. Viewers comprehension and appreciation of newscasts, sportscasts, magazine type shows, and music videos which use complex and visually overloaded settings is minimal. In particular, viewers' appreciation of digitally produced television sets often utilized in such programs is minimal. When the harmonious co-existence of the compositional principle known as figure/ground relationship is ignored, the television pictures are incomprehensible and annoying. A visual performance in the background usually overshadows the foreground (the figure) and vice-versa (Nevitt, 1980-81). The setting in television picture composition plays a much greater role in picture composition than contemporary television producers/directors wish to acknowledge (Coldevin, 1981; Baggaley et al., 1980). In summary, we have the technology to create responsible television programs, comprehensible and appreciated by all levels of viewers. We must not forget that the emphasis should be on communication rather than visual gimmicks. Studies in educational technology and visual communication media must play a protagonistic role towards this goal.

\section{FUTURE PREDICTIONS AND SUGGESTIONS}

Although scholars of the television medium are reluctant to make firm statements of the effects, positive or negative, of computerized television production techniques on contemporary viewers, the research and development departments of the television industry have no difficulty at all making such future predictions (Hodes, 1986). Academics wonder how we are going to deal with an ever-increasing, rapidly changing television technology when we have a hard time understanding the effects of the present developments. The television industry, however, is not so sensitive to such questions. Since they lead the way in television technology, it is easy for them to predict future developments and trends. A chief executive for Sony Broadcast Productions, for example, a few years ago stated flatly that:

\footnotetext{
In 1984, we moved one year further into the era of not what can technology produce-but what should technology produce? To a great extent, that question will have to be answered by the users. Their needs should determine the direction of future technological developments. As an industry, we now have the power to shape technology to meet user needs (Hodes, 1985).
}

This is ironic if we consider how powerless the user/viewer is and how powerful technology is. This is a paradox of our times with which we are confronted and must provide some solutions.

In a key article titled "A Glimpse Into Future Television", Nadan (1985) provides some insightful prophecies stemming his laboratory research. Nadan (p. 135) summarized the future of television technology improvements as follows: 


\begin{abstract}
The next generation of television receivers, in order to gain our acceptance, will most likely have 1) a large display area with a wider aspect (width to height) ratio, 2) flexibility and interactivity, 3) approximately twice the perceived horizontal resolution and vertical resolution of NTSC (National Television System Committee) television, 4) true highfidelity stereophonic sound (not discussed here), 5) new artifacts (visible effects on the display; for example, shimmer and colour flashing) that were not present in the original scene.
\end{abstract}

It is apparent that commercial television will dictate major advances in two areas - information and entertainment. The relationship between HDTV and two way interactive and cable television will develop video shopping. Computer generated data and direct broadcast system through satellite will increase news information and public affairs programs and will make direct and instantaneous global communication of information possible. The developments of digital memories within the television receiver will open up the possibility of watching more than one program simultaneously, and HDTV will generate longer and wider pictures on bigger screens for home use.

These major future changes, along with a plethora of minor ones (not dealt with in this article) will occur whether we want them to or not. Our challenge and our mission as educators are: a) to alert our students to these matters: b) to inform the viewers of the possible covert effects of these technologies; and c) to work systematically and try to redirect the scope of these inventions by working hand in hand with the industry developers.

First, as the industry decides the future developments of television technology, so should we, the educational communication teachers, decide the future developments of our society at large. It is our responsibility to emphasize vigorously, and to work feverishly to alert our students and our peers to these developments. As educational communication instructors, teaching our students the use of the media in communication, we are often not adequately informed of the covert effects media technology might have on viewers. Unless we engage in vigorous research on such matters, our teaching of the media will always be unsustained and our students will not be properly informed. Considering that the future will be shaped by our students we must prepare them adequately.

Second, we must engage our students, our peers, and ourselves in vigorous research in all aspects of television production. Empirical studies in educational television technology, television composition, and television aesthetics are very scarce (Metallinos, 1985). For a long time, and for different reasons, scholars in these areas have neglected to study the components of the television system, or the processes involved in the synthesis of televised messages, in view of studies dealing with the content of television programs. Sporadic attempts to undertake such research have been made by Zettl(1973; 1976), Tiemens (1970; 1981), Coldevin (1976, 1981), Baggaley (1978), Baggaley et al., (1980), Metallinos (1977), 1986), etc. However, the field remains wide open. We must focus our efforts on the study of the variables related to television production. Such studies will allow greater and more precise predictability of the covert effects of television technology on viewers' awareness, comprehension, and appreciation of televised images. As Zettl points out: 


\begin{abstract}
For some reason, aesthetic factors in television production and methods of presentation, or even the aesthetic potential sand requirements of the television medium, have not been considered as an area of serious research. Whatever the reasons for this inactivity may have been, we simply can no longer afford keeping our backsturned to thestudy of television aesthetics. $(1982$, p.9)
\end{abstract}

Wide publication of such research findings inevitably will reach the viewers.

Third, in order to prevent the potential development of frivolous and destructive television production hardware, we must encourage our television production scholars to actively participate in research and development departments of the television broadcasting industry. Today, very few scholars and serious researchers of educational television production and television aesthetics are involved in the industry. The dialogue that occasionally occurs between broadcasting industry personalities and broadcast education scholars is good but not sufficient. Manageable, more systematic, and more formal ways must be found to engage these polarized worlds in common research in television production hardware. We are all responsible for the future of television. We all depend on it. The research and development of the television industry should not run so far ahead of the research publications of television scholars or without their mutual understanding and cooperation. We must all be responsible for the welfare of human beings exposed to television's indisputable power.

\title{
SUMMARY AND CONCLUSIONS
}

This article deals with the issue of television technology versus television aesthetics. The intentions behind the developments of such extraordinary and advanced computerized television technology are challenged.

The first part briefly examines the technological advances of the last decade in the major television production units such as cameras, lights, audio, switchers, and recorders, 3-D video, cable TV, and direct satellite broadcasting.

The second part discusses the application of these technologies to such key television programming genders as newscasts, sportscasts, magazine type shows, and music videos. An effort is made to point out the potential covert effects such programs might have in terms of viewers' total awareness, comprehension, and appreciation of their visual content.

The third part of the article provides some information based on existing literature on the future direction of the development of television production hardware. It underlines the potential consequences such developments might have on information and entertainment programs. Finally, it suggests that responsible teaching of television's influences on viewers, publication of scientific research on television production related variables, and the direct involvement of academics with the television industry might help us to better understand and control the future trends in television production developments.

It should be evident from the issues raised and discussed here that technological developments in the television industry are often insensitive to the covert effects the application of these technologies might have on the average viewer. The television 
industry, trapped by the competition for higher ratings, often employ new hardware in programming before it is properly tested. Consequently, any covert effects such programs may have on viewers are left to chance. Educational communicators and media scholars should be alert to not allowing television's computerized technology to overshadow the aesthetics of televised images.

\section{REFERENCES}

Amopolos, P. (1982). Political dimensions on an information society: A general overview. GAMMA Group. Montreal, Quebec.

Baggaley, J. Ferguson, EM., \& Brooks, P. (1980). Psychology of the TV image. New York: Praeger.

Baggaley, J. (1978). Television codes and audience response. Journal of Educational Television, 4, 24-29.

Bernard, R.M., \& Coldevin, G.O. (1985). Effects of recap strategies on television news recall and retention. Journal of Broadcasting and Electronic Media, 29, 407-419.

Calvert, S., Huston, A., Watkins, A., \& Wright, J. (1982). The relation between selective attention to television forms and children's comprehension of content. Child Development, 53, 601-610.

Chartrand, S. (1986). Direction and speed of motion on z-axis staging: Effects of the recall of information. Paper presented at the Communication Studies Colloquia 1985-86, Concordia University, Montreal, PQ.

Coldevin, G.O. (1975). Space massed, and summary treatments as review strategies for ITV productions. Audio Visual Communication Review, 23, 289-303.

Coldevin, G.O. (1976). Comparative effectiveness of TV production variables. Journal of Educational Television, 2, 85-93.

Coldevin, G.O. (1981). Experimental research in television message design: Implications for ETV. Program Learning and Educational Technology, 18, 86-99.

Costello, M. (1985). The big video picture from Japan: The future is projected at Tsukuba Expo '85. Videography, 10, 27-31.

Coumuntzis, G.M. (1987, July). Children's comprehension of changing viewpoints in visual presentations. Paper presented to the Visual Communication Conference, Alta,UT.

Epstein, W. (1977). Stability and constancy in visual perception: Mechanisms and processes. New York, NY: John Wiley and Sons.

Fletcher, J. (1984). The new electronic media: Boom or bust for the arts? Paper presented at the Faculty Seminar of the University of Georgia, Athens, GA.

Gerbner, G., Cross, L., \& Melody, W. (Eds.). (1973). Communications technology and social policy: Understanding the new cultural revolution. New York, NY: Random House.

Green, K. (1983). 3-D video: Another step. Video Systems, 9, 24-29.

Gzesh, S., \& Surber, C. (1985). Visual perspective- taking skills in children. Child Development, 56, 1204-1213. 
Hodes, D. (1986). Stereophonic versus monophonic sound in a television program and its impact on the viewer. A Thesis for the M.F.A. Degree, Temple University, Department of Radio-Television-Film, Philadelphia, PA.

Kreckel, R. (1985). Light source: Studio lighting in the new ZDF television production centre. Broadcast Technology, 11,46-50.

Lang, B. (1976). The big screens. Videography, 1, 24-27.

Mathias, H., \& Patterson, R. (1985). Electronic cinematography: Achieving photographic control over the video image. Belmont, CA: Wadsworth.

McCain, T.A., \& Divers, L. (1973). The effect of body type and camera shot on interpersonal attraction and source credibility. Journal of Broadcasting, 21,35-46.

McDaniel, D.O. (1974). Television news film: A study in audience perception (Microfilm). Ann Arbor, MI: University of Michigan.

McLuhan, M. (1964). Understanding media: The extensions of man. New York, NY McGraw-Hill.

McPhail, T. (1986). Electronic colonialism: The future of international broadcasting and-communications. Beverly Hills, CA: Sage.

Metallinos, N. (1979). Composition of the TV picture: Some hypotheses to test the forces operating within the television screen. Educational Communication and Technology Journal, 27, 205-212.

Metallinos, N. (1985). Empirical studies on television composition. Broadcasting Research Methods. In J.R. Dominic \& J.E. Fletcher (Eds.), (p. 295-311). Boston, MA: Allyn \& Bacon.

Metallinos, N. (1986). Visual space: Empirical research in television z-axis staging. Humanism in a Technological Age: Communication Arts Studies: 1965-1985. Concordia University, Montreal, Quebec.

Metallinos, N. (1987, June). Computerized television: New developments in television production techniques. Paper presented to the Symposium on Verbo-visual Literacy, Stockholm, Sweden.

Nadan, J. (1985). A glimpse into future television. Byte, 10, 135-150.

Nevit, B. (1980-81). Visible and invisible bias via media. Canadian Journal of Communication, 7, 9-42.

Paulson, K. (1984). State of the art techniques: Postproduction in 1984. International Television, 2, 40-46.

Rogers, M. (1986). Communication technology: The new media in society. New York, NY: Free Press.

Schubin, M. (1981). Video research: He-de, hi-de, hi-de, no? Moving movieward. Videography, 6, 74-77.

Schubin, M. (1986). Cheap thrill. Videography, 10, 68-71.

Talen, J. (1986). How the camera changes the game. Channels, 6, 50-55.

Thomson, E., Reeves, B., \& Schleuder, J. (1985). Message complexity and attention to television. Communication Research, 12, 427-454.

Tiemens, R.K., \& Acker, S.R. (1981). Children's perception of changes in size of televised images. Human Communication Research, 7, 340-346.

Treisman, A. (1986). Features and objects in visual perception. Scientific American, $225,114 \mathrm{~B}-125$. 
Valaskakis, K. (1980). The information society program. Gamma Group. Montreal, PQ. Westport, D. (1986). Film and video: The CCD concept. Video Systems, 10, 28-30.

White, S.E. (1986). The effect of television's visual complexity on information identification/recognition. Communication Research Reports, 3, 153-157.

Wright, C. (1959). Mass communication: A sociological perspective. New York, NY: John Wiley \& Sons.

Wurtzel, A.H., \& Dominick, J.R. (1971-72). An evaluation of television drama: Interaction of acting styles and shot selection. Journal of Broadcasting, 16, 103110 .

Zettl, H. (1976). Television production handbook (3rd ed.). Belmont, CA: Wadsworth.

Zettl, H. (1982). Research in television aesthetics. Spectra: Newsletter of the SCA, 18, 9.

Zettl, H. (1984). Television production handbook (4th ed.). Belmont, CA: Wadsworth. H. (1986). The graphication of television news and the personification of the news anchor. Paper presented at the Communication Studies Colloquia 1986-86, Concordia University, Montreal, PQ. 


\title{
Profile
}

\section{The Renfrew Quality Education Project: Teachers' Views After the First Year}

\section{Donna Sharon}

\begin{abstract}
The Renfrew Quality Education project was designed to train teachers in using television as an educational tool that can support the child-centered teaching strategies being encouraged by the school board. This project was developed cooperatively by the Renfrew County Roman Catholic Separate School Board and TVOntario, the provincial educational broadcast network. Design of the project was guided by a collegial approach to teacher training and a strategy for implementing change formulated by Michael Fullan at OISE.

Based on interviews conducted after the first year, this paper presents teachers' reports on how the project affected their teaching and how their students' behaviour and learning were affected as a result. Summaries are presented of the teachers' initial activities in working with other teachers, of their observations on the training sessions provided by TVOntario, and of their suggestions for the next phase of the project.
\end{abstract}

As one component in a board-wide move toward child-centered teaching practices, the Renfrew Quality Education Project was introduced to train teachers in how to use television programming effectively in their classes. Prior to the project's conception, the Renfrew County Roman Catholic Separate School (RCSS) Board in Ontario had introduced several measures to encourage the approaches and practices described in The Formative Years (1975) and Shared Discovery (1985), two guidelines issued by the Ontario Ministry of Education. These documents emphasize the developmental needs and styles of individual children, with the goal of helping students become independent problem solvers. Strategies to support this child- centered view include increasing opportunities for children to interact both with teachers and with other children, and to undertake activities suited to their individual learning patterns. In developing this project, the board worked cooperatively with TVOntario, the provincial educational broadcast network, whose Educational Services Branch produces support materials for school television programs and offers teacher training activities. An extensive network of Television Resource Teachers - TRTs - distribute materials and encourage television use.

Donna Sharon is a Senior Research Officer working in Planning and Development Research at TVOntario, Box 200, Station Q, Toronto, ON M4T 2T1. 
As the project began, some teachers were already using available school television programs. The project planners, John Stunt, Superintendent of the Renfrew RCSS Board, and Marcia Cunningham, Educational Development Officer at TVOntario, hoped to "change the attitudes and practices of teachers, while helping to produce selfdirection and critical thinking in students" (Cunningham, 1986). After participating in the project, teachers were expected to have learned how to use television equipment, view programs critically, and plan lessons that relate television programs to curriculum objectives. In their teaching they would use television programs, along with related classroom activities, in ways that encourage students to participate and become critical viewers.

Another aspect of this project was the adoption of a collegial approach to teacher training. Initially, eight teachers were involved and trained with the expectation that, once they felt confident using television effectively, they would work with other teachers in modelling for them and encouraging them in adopting similar strategies. This peer-coaching strategy represents a new approach to professional development for teachers (Joyce \& Showers, 1980; Little, 1985).

In planning this project, the model for implementing change in schools, developed by Fullan (1985), was used as a guide. In keeping with his view of change as a gradual process, a two- to three-year time frame was agreed on. Stunt and Cunningham, the project designers, received commitments of considerable resources and support, including three days of release time for participating teachers from all levels of the Renfrew RCSS Board.

Principles of adult education, which view adults as self-directed learners, were also incorporated, both to promote the teachers' learning and as examples of the strategies they were being encouraged to use with their students. Many ideas and options were presented to the teachers but no precise expectations were defined. Rather, teachers were encouraged to design personal performance contracts to direct and monitor their own progress.

Marcia Cunningham prepared and led workshops for the varied group of five women and three men, including six elementary teachers (one teacher/principal) from different grades and two high school teachers. Two training days were held during the 1985-86 school year and two more in the Fall of the 1986-87 school year. Figure 1 summarizes the main objectives and activities of the training sessions. Between training days, teachers' contact with the project was maintained by telephone calls from Cunningham and by encouragement from the principals, school board staff, and trustees.

While working in Planning and Development Research at TVOntario and studying part-time with Fullan at the Ontario Institute for Studies in Education, the researcher became interested in the process of implementing change in schools and learned of the Renfrew Project as it was being developed. Following lengthy discussions with Cunningham during the design stage, the researcher proposed conducting interviews with the teachers to look at the project from their perspective. In model for implementing change, monitoring the project's progress is recommended as a way of identifying problems and guiding development.

In February 1987, toward the end of the project's first year, the researcher 
interviewed all eight teachers directly involved with the project about their experiences - their use of television, involvement with other teachers, views of the training, and suggestions for the remainder of the project. Structured, one-hour interviews were held and taped in the teachers' schools. The tapes were later transcribed. The next section of this paper summarizes the teachers' views and reports their experiences. The last section relates their views to the objectives set in the project's design and discusses the questions and issues ahead.

FIGURE 1. Training Objectives and Activities.

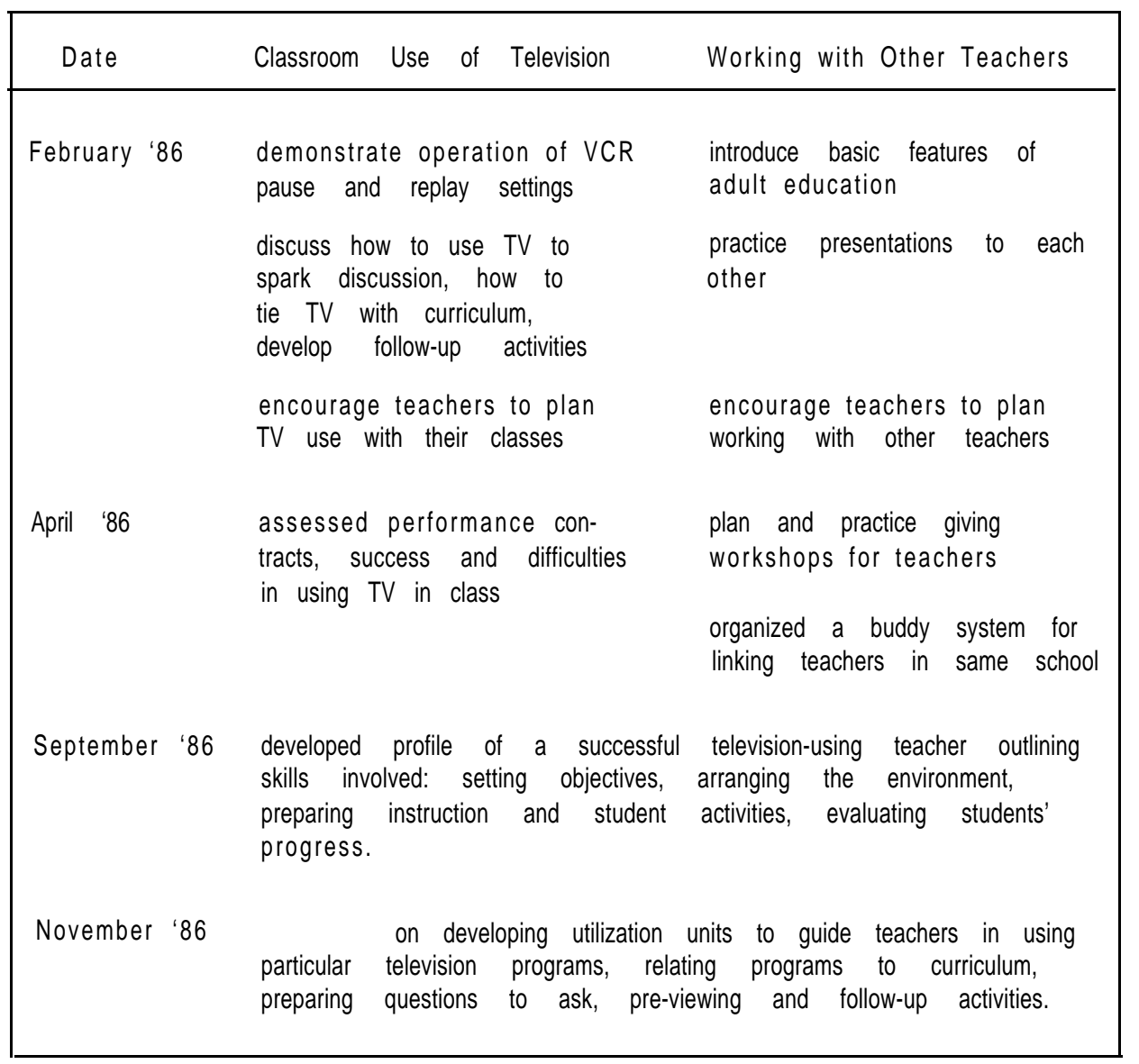

\section{TEACHERS VIEWS}

Impact on Teaching

All of the teachers involved found the training in classroom use of television very valuable. Four of the teachers began the project with skeptical or critical views of television in school. One teacher said, "I wasn't really into TV . . I felt that children see 
X number of hours of TV at home." Another teacher "was a firm believer that children watch too much television. . When we finally did get a TV and VCR here, I didn't really realize what its function was all about"

Several teachers pointed out that the TV is sometimes used as a filler, particularly just before holidays or weekends. After learning to preview critically and to use the technical capabilities of VCRs in their classrooms, the teachers felt that they had control, that TV was an effective teaching tool that they could use to get students active and involved.

The five teachers who had used TV to some extent before the project appreciated the opportunity to talk with other teachers and hear new ideas about classroom techniques. Two teachers mentioned the value of television in subject areas they were weak in such as music or science.

The teachers also saw many ways that using television could support a more childcentred approach, aiming to encourage independent thinking and problem-solving skills. Well chosen programs or short clips were found useful in starting lively small group discussions and in sparking students to pick their own topics for further study. "Everyone who follows the programs and uses the guides finds that there are plenty of follow-up activities, plenty of choice I found that the programs do promote the curriculum renewal within our Board It's a tool."

Another teacher had the students plan follow-up activities. 'They'll get ideas from the tape and then they'll think of what else they could do. they came up with ideas."

Compared to the enthusiastic assessments of using television in their teaching, the difficulties and adjustments teachers reported going through seemed modest. Only a few problems such as stolen equipment or awkwardness with window blinds were mentioned. Teachers found that beginning to use television took extra time. "I have to spend some extra hours putting together sort of activity booklets for my kids and stuff like this . I think if you don't do some of this type of development, you sort of lose the flair."

\section{Impact on Students and Their Learning}

As one teacher pointed out, "You have to look at the children's interest in it, how they respond to the TV itself. . . Otherwise, you know, I wouldn't use it if it wasn't working." Teachers' reports of student interest and involvement were very favorable. The attention-getting and motivating aspects of television were mentioned repeatedly. Teachers reported a variety of benefits for and from their students:

I could not believe how much they had retained, which I know they would not have retained if I had all my maps and my charts and we had gone at the Seaway the traditional way.

I found I got more quality stuff with the visual than they did with just the reading lessons ... The quality, their answers, their sentence structure, not just the creativity, everything was better.

Some teachers commented on the media sophistication of their students:

Children know how to get information from the television better than we do. They're brought up on it I've had instances in which they will pick things out that I don't see. 
Teachers also saw changes in their students' attitude to watching television, both in class and at home.

They were thinking of television as being entertainment and I really had to push them in the beginning. I really talked to the them a lot ... I found by the second week they realized this was different.

Stopping the program several times for questions and discussion changed the students' expectations and encouraged them to be critical.

Teachers reported successful experiences using television as a teaching tool but they also pointed to some reservations. Some teachers felt that certain programs would be more useful and easier to use if they were more closely related to the curriculum. They also felt that television is a tool to be used in moderation-using only one series at a time or using three- or four-minute. clips to get things stated. The costs in terms of time are. discussed later. But overall, the teachers' comments indicated that the project enhanced their use of television and contributed to successful experiences for the students.

Most teachers still preferred to use television sparingly - only one teacher greatly increased the amount of television she was using. For several teachers, their views of television meshed with a changing view of their students and, as the project designers hoped, connections were made between using television and increasing student participation in activities related to their individual preferences. Gains in students' critical thinking and self-direction were suggested as well in the teachers' comments.

\section{Working with Other Teachers}

From the beginning of the project, the eight teachers were called model television teachers (MTTs) -a name some didn't like-to reflect the expectation that they would gradually become involved in training and encouraging other teachers in using television in their classrooms. This process was only in its beginning phase. No specific expectations were set out for the role that each of the model teachers would play.

Rather, TVOntario staff gave presentations in workshop techniques and in principles of adult education, and outlined several options that the teachers could choose to pursue. In keeping with the adult education model, performance contracts were introduced to encourage teachers to consider and choose activities they would like to carry out between training sessions, and for monitoring and assessing their own progress. So far, six of the eight teachers have designed and tried out activities involving other teachers.

In the interviews, these teachers described the activities they've undertaken so far and what they thought the results were. Four of the elementary teachers became very active and involved in giving workshops, in working with individual teachers in their classrooms, and in one case, organizing weekly noon-hour tape viewings and discussions, and developing television support materials as well. These teachers seemed very comfortable and eager to work with other teachers in their schools. In one case, the model teacher took one or two programs and the teacher's guide from the primary social studies series We Live Next Door to a meeting to introduce the series and discuss it. He then followed up by going to the classrooms himself and teaching one two lessons. Another teacher who had shown and discussed television programs with staff in her school was pleased with a colleague's progress. 
Another elementary teacher was active in organizing several workshops and presentations with parents as well as a small group of teachers. The fiith elementary teacher had several frustrating experiences in getting the programs and the teacher's guides. She then arranged, instead, to work with TVOntario in developing support materials which help teachers prepare to use programs, relate them to curriculum, and plan follow-up activities. The sixth elementary-level teacher in the project only joined the project during the 1986-87 school year. Having missed much of the training, she did not yet feel ready to work with other teachers but was expecting to start soon after the interviews.

The two high school teachers in the project got together and organized an afterschool workshop for English and Student Service teachers in their school. While these two teachers felt that they learned a lot in preparing the workshop and that their efforts were well received, they did not see any future for themselves in giving workshops. Since high schools are organized by subject departments, people with expertise in each area and familiarity with the related television programming would be necessary to work with teachers in other subject areas.

There's a little problem in how does the TVO project see this modelling concept (work) in a high school setting... I'm teaching English but now what do I do for science...it breaks down a little bit in high school versus elementary.

In talking about working with other teachers, one teacher said:

One of the resentments is that you still have your classroom to prepare.... you have

to get all that work in advance. You're never totally released because you have to prepare. It's a lot of work to do in advance to leave behind, and it has to be suitable work My biggest problem in teaching is time. There are so many things in life I want to do and teaching is consuming so much as it is. I just could not imagine doing more.

Working with other teachers was identified as the area most in need of attention during the rest of the project Individually, most of the teachers have identified the kinds of activities they would like to become involved in, but there was only a vague idea of how the project as a whole will develop in reaching other teachers and whether both the first group of teachers and the new teachers will be given time to do this type of work. This issue is discussed further in the final section.

\section{Training}

Four training days had been held so far - two during the 1985-86 school year and two held early in 1986-87. Several of the teachers have found the sessions valuable in offering demonstrations of classroom techniques given by the leader and by other teachers, and in showing new programs for all grade levels. One teacher emphasized the importance of learning about VCRs:

I learned how to use the remote control how to pause, how to use my reset and my memory and use it properly to pause and ask them questions, how to use it effectively.

Some of the teachers, however, were left overwhelmed and intimidated after the 
first session, feeling that the expectations were too great or feeling let down when they returned to their classes.

I don't think I was the only one. I know I'm not because I talked to a few others that felt kind of overwhelmed at the beginning. And I'm just wondering if it couldn't have been that that anxiety couldn't somehow have been omitted by another approach.. The first time we went we got into giving workshops. I didn't know how to turn the VCR on ... Now I don't know whether they realized that after because we took it a little slower from then on.

Not all of the teachers attended all of the sessions, and invariably, joining the project late or missing a session in the middle, created problems for the teachers involved. One teacher who missed the first session mentioned several times during the interview that "I always had the feeling I was catching up." After missing one meeting, another teacher said, "when I came back I could just feel that everybody was kind of going into different little areas."

As mentioned earlier, teachers used performance contracts as aids in setting goals for themselves and monitoring their progress:

I like the performance contracts. It's a sense of accomplishment. For me, it's a check list and I find it a very good way to organize what you're going to do for that particular time in between meetings.

The teachers were asked how this training compared with other training with which they've been involved. Most teachers felt that this program was unique in being small, personal, accepting of individual differences and needs, and continuous over many sessions.

Overall, Cunningham's presentations, the workshop simulations, the work with television programs, and the use of performance contracts to help teachers direct and supervise themselves were all weIl received. The first session seems to have moved too quickly and an adjustment period was needed for teachers to learn to use the performance contracts, to realize that they were expected to formulate expectations themselves, and that external pressure was very limited. But, once the project's pace was established, the teachers seemed to thrive.

\section{Support from Principals and the Board}

Based on his review of research, Fullan concludes that active support from principals is crucial to a project's success, 'Principals' actions serve to legitimate whether a change is to be taken seriously (and not all changes are) and to support teachers both psychologically and with resources." At the same time the role of school board officials is essential (Fullan, 1982).

Our principal and some parents organized a mini-sports day for the children.

So you see it gave us an hour-and-a-half one day and we sat down and viewed a program, the teacher and I, so I was able to show them using the remote control and discuss the program.

I've always found the Board very supportive when it comes to trying to better the quality of education we have for students. They pick up on suggestions 


\section{CJEC WINTER 1966}

and give you credit for any suggestion that you may give. They're very compassionate and they're very understanding of the human aspect, it's not that you're looking for a pat on the back, but when it's there it sure makes it a lot easier.

All of the teachers felt commitment and encouragement from the Board, reflected in John Stunt's support, the availability of equipment and programs, and some release time. While most teachers were also getting support from their principals, one teacher felt that the school principal was not particularly interested in the project, although he didn't stand in the way. "He wouldn't come down here. . he hasn't been in to see what I'm doing or hasn't asked . . if I asked him for something, he'd give it to me? While the causes are not clear, this teacher did in fact report greater frustrations with the project than did the other teachers.

\section{Ideas for the Next Phase of the Project}

When asked about their suggestions for the next phase of the project, the teachers' greatest concern was the extension of good educational television into other classes and the role they themselves could play. All of the teachers felt that more release time is needed if they are to become more involved in working with teachers.

One teacher focused on the need to produce more curriculum-related utilization materials to make it easier for teachers to "se the programs. Several teachers felt that workshops are of limited "se and stressed the need for trained people in each school who will promote TV "se in their school on a day-to-day basis. One teacher emphasized that she would rather do in-class demonstrations to bring the ideas to the teachers: "I would prefer to work with children if I'm going to present. I would prefer to use someone's class rather than give it to a group of teachers. Just so they then see it can be realistic."

Finally, a couple of teachers would like additional training in presentation skills and ongoing training in classroom "se of television. The implications of these diverse views of what is needed and how the project should move are discussed in the following section.

\section{DISCUSSION AND IMPLICATIONS OF THE TEACHERS' EXPERIENCE}

The teachers' perspectives as presented in the previous section point to several areas for consideration in planning the next phase of the project. Implications of the teachers' comments for understanding of the change process and for design of future projects are indicated as well.

1) The project is having considerable success in fostering the "se of television as a" educational tool and in relating the "se of television to the Board's broader concern with child-centered teaching. Further research could look more closely at such areas as how television use can combine with particular teaching styles and learning outcomes and how the development of critical viewing skills can be encouraged. 
2) The project provided effective training in using television in the classroom, gave teachers the opportunity to share ideas about television "se, and maintained ongoing contact with the teachers while they tried it out. However, their successful experience in the classroom was crucial - their reports supported previous research findings which show that teachers change as a result of successfu1 experience (Fullan, 1982; 1985).

3 ) The value of seeing change as a lengthy process requiring ongoing personal contact and support was strongly supported by the teachers' comments. Not only did they identify the long-term support as an essential feature of this project but some were extending this support in their suggestions for working with other teachers. While workshops were seen to have some value, an ongoing involvement on an individual or small group basis was seen as the key to spreading the use of television to more schools and classrooms.

4) The use of an adult education approach in conjunction with this ongoing support contributed to the teachers' positive experiences. The performance contracts were a successful means for helping teachers select the activities they would like to pursue and assess their progress. Although considerable frustration was involved as teachers overestimated the amount they could do at first, or felt that there were unspoken expectations of them, the ongoing support provided helped them ride through this phase. and find gratification in working independently. This initial difficulty and gradual recovery is typical of the change process (Fullan, 1982; 1985). Ongoing use of performance contracts with this group and with other teachers as they become involved is warranted.

5) Consistent with adopting an adult education approach, the project has had very open-ended goals, allowing the teachers to make choices that shape the project's direction, rather than specifying expected results in detail. Given this freedom, each teacher has developed a unique combination of activities and objectives, including one or more of the following:

- using classroom television well;

- giving good presentations for small groups:

- developing successful workshops;

- following up with teachers after group events;

- inviting teachers into their classroom;

- teaching lessons in another class; and

- relating programs and curriculum and developing utilization materials.

6) The project includes teachers at all grade levels and in several subject areas. Although two teachers found the varied group a positive experience, others would have preferred to be with teachers in the same grades or divisions. This was a particular problem for the high school teachers who found that the subject department structure of high schools limited their ability to work with other teachers.

7) In all aspects of the project, but especially in working with other teachers, the project teachers felt pressed for time and in some cases drained by the extra 
workload. While working with other teachers and students can be useful for their professional growth, some teachers felt that their own day-to-day teaching suffered when they became involved in planning and giving workshops or working with other teachers on more than a very occasional basis.

8) Teachers felt at a substantial disadvantage when they missed even one training session, no matter how unavoidable the absence was.

9) The teachers described support from their principals, who in most schools asked about or sat in on classes where television was being used and helped teachers arrange release time. Similarly the teachers felt that the board was behind the project, providing video equipment and tapes, support services, release time and personal encouragement from John Stunt. Their commcnts support earlier research which emphasizes the necessity and value of such support (Fullan, 1982).

10) Perhaps because of the costs involved in training and supporting television use in schools, some teachers questioned the future direction of the project. Although one teacher described the television equipment and programs as a cheap source of worthwhile educational materials, the question was raised whether the training aspect was too costly to be a priority, compared to other needs in the board.

While this paper cannot compare the value of this project with alternative ways of using the resources involved, it does suggest that the project has been proceeding successfully. The teachers' reports indicated they had learned new strategies for using television in child-centered ways with their students and that with additional release time they would be interested in extending this expertise to more teachers. In the coming phase of the project, it can be expected that the board will gain both a larger number of teachers skilled in using television as a classroom tool and additional firsthand experience with the peer coaching approach to teacher training.

\section{REFERENCES}

Cunningham, M. (1986). Description of the Renfrew Project. Toronto: Educational Services Branch, TVOntario.

Fullan, M. (1985). Change processes and strategies at the local level. The Elementary School Journal, 85 (3). 391-421.

Fullan, M. (1982). The meaning of change. Toronto, ON: OISE Press.

Joyce, B., \& Showers, B. (1980). Improving inservice training: The messages from research. Educational Leadership 37, 319-385.

Little, J. (1985). Teachers as colleagues. San Francisco, CA: Far West Laboratory for Educational Research and Development.

Ontario Ministry of Education (1985). Shared discovery: Teaching and learning in the primary years. Support document to The formative years. Toronto, ON: Author.

Ontario Ministry of Education (1975). The formative years. Circular P1J1, Provincial curriculum policy for the primary and junior divisions. Toronto, ON: Author. 


\title{
Microware Review
}

\author{
Len Proctor
}

\section{Apple's HyperCard \\ Reviewed by Earl R. Misanchuk}

Before I actually tried out HyperCard, I had read a number of reviews of it in the popular press. What intrigued me about those reviews were the waffle-words that were used to describe what kind of software HyperCard was. My expectation, based on those reviews, was that HyperCard was sort of a database program, but not really; much like hypertext, but not exactly; kind of a programming language, but not really a programming language because even non-programmers could understand it. And oh, yes, it contained all of MacPaint, plus a number of features MacPaint didn't have.

Now that I've had an opportunity to actually work with HyperCard, I can unequivocally state that HyperCard is sort of a database program, but not really; much like hypertext, but not exactly; kind of a programming language, but not really a programming language because even non-programmers can understand it. And oh, yes, it contains all of MacPaint, plus a number of features MacPaint doesn't have.

Rather than attempt to force-fit HyperCard into one of the extant categories of software types, let me try to describe one or two uses to which HyperCard can be put. Then perhaps you will agree with me that HyperCard is sui generis. (Whether it will remain the only exemplar of its class or whether competing products will develop to challenge it is a topic of much debate on the computer networks today.)

The name HyperCard implies the metaphor on which the program is based: a stack of cards, each containing information. They are not ordinary cards, however-they are definitely "souped up" enough to deserve the prefix "hype? Cards can contain text, graphic elements, buttons ("live" spots on the screen which, when clicked upon, cause something to happen, e.g., movement to another card or stack), and simple sound. Users can move from one card to the next in either direction through the stack, or to another card elsewhere in the stack. Furthermore, the user can blithely move to a card in another stack, then back to the first stack, with absolute transparency. The movement can be done under the control of the user or of the author of the stack.

Let me describe a few stacks that come with the program, in hopes of giving you a

Len Proctor is an Associate Professor of Educational Communications at the University of Saskatchewan, Saskatoon, Saskatchewan.

CJEC, VOL. 17, NO. 1, PAGES 63 - 66, ISSN 07104340 
fuller picture of what HyperCard is and can do. There is a basic rolodex emulator, which can be used to store addresses and phone numbers (a standard database-type application). It can also be used, in conjunction with a modem, to actually dial the phone numbers for you. To use the rolodex, users simply add or modify text to the onscreen representations of rolodex cards, using standard Macintosh editing techniques. Of course, cards can be added, deleted, copied, etc. MacPaint-like graphics can be used to add visual components to cards, as well.

There is a calendar which, when you click the mouse on a particular date, becomes a weekly calendar book for the week containing that date. This ability to bring to the fore some related information by clicking on a certain spot (called a button) is strongly reminiscent of hypertext programs (e.g., OWL's Guide). Also linked to the weekly calendar and yearly calendar is a To Do list, Click on a certain date and the To Do list for that date appears. This ability to link the three separate stacks together, functionally, is reminiscent of a relational database program.

There are a couple of other idea-generating stacks that illustrate what kinds of information can readily be stored in HyperCard form, using quotations and clip art as the subject matter. Some of the 19 assorted stacks that come with the programs illustrate a few of the other things HyperCard can do: It can store graphic images as readily as text; it can sort cards according to criteria you specify; it can flip rapidly through all the cards in a stack; it can search through a stack for a user-specified keyword(s) with incredible speed, without any need for limiting the search to specific fields. Indeed, one of the reasons that HyperCard may well continue to be unique for some time is the fact that it contains new, copyrighted algorithms for extra-rapid searching. How does a three-keyword, field-free search through 50,000 cards, in under two seconds sound? (I haven't done it myself, but a usually reliable source quoted those figures to me.)

One of the stacks, the Help stack, is a sight to behold. It is unquestionably the finest example of internal documentation these tiredeyes have ever seen. The obvious care given to its instructional design is typical of Macintosh program manuals, but not at all typical of help files, on the Mac or (especially) in the MS-DOS or mainframe worlds. Profusely illustrated, well explained, and demonstrating many of HyperCard's powerful features itself, it can be a more than adequate introduction to the program by itself, if for some reason you can't locate your manual.

The power of HyperCard begins to become evident when the user progresses beyond using existing stacks and begins customizing them for specific uses. For example, the first thing that came to mind when I explored the sample stacks was HyperCard's potential for doing literature searches (in the sense of finding common elements within summary notes made on various articles and books). As I experimented with HyperCard, my eyes drifted upward to the spot on my shelf where my 15year-old collection of keysort cards languished. Given HyperCard's rapid search capabilities and freedom from restrictive fields, I almost wanted to go back to being a graduate student again. (I suspect I risk the wrath of today's graduate students when I say "It would be so easy now!")

But the real power of HyperCard shows itself only when the user progresses to the level of what the HyperCard manual (which itself is a typically Macintosh, high-quality 
instructional device) calls authoring--creating new HyperCard stacks from scratch. The manual covers the basic procedures of stack creation adequately, but only hints at what can be done if the author is willing to venture into the realm of HyperTalk, the programming language that forms an integral part of HyperCard. What can HyperTalk do? Too many things to go into detail on in this review, but all with a very English-like language. Does the following sound like programming?

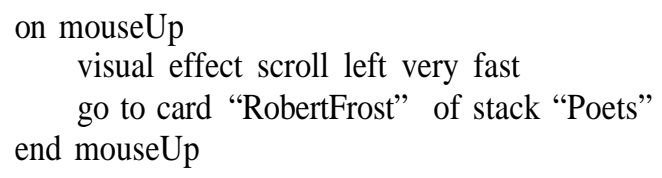

Or does this sound like programmmg?

on mouseUp

if the first character of the message box is in "0123456789("

then dial the message box

else

Ask "Dial what number?"

dial it

end if

end mouseUp

Well, maybe just a bit. But notice how easy it is to understand? HyperTalk will happily execute those instructions.

Simple animation is possible. So is sound (even simple music). Question asking and answer checking. Card and stack protection, with or without passwords. So are reading files, launching applications, and a great deal more. Easily, without great gobs of time spent learning how to program to get it.

ASIDE: If you are serious about wanting to get involved in authoring, you should acquire Danny' Goodman's hefty (720 pages) paperback, The Complete HyperCard Handbook (Bantam). The first half of Goodman's book provides a more in-depth treatment of HyperCard's features than does the actual HyperCard manual, along with many hints and shortcuts. The second half is devoted entirely to HyperTalk. The book is very well written, in language understandable to a non-programmer, even the part on programming (obviously, some experience in programming certainly wouldn't hurt, however).

Does this all sound too good to be true? Here's the final straw: Apple now gives away HyperCard with every purchase of a Macintosh Plus or Macintosh SE. If you've owned your Mac for a while, you can buy the program from Apple dealers for around $\$ 50$ (educational price).

There has to be a catch, right? Well, maybe a small one: HyperCard will only run on a Mac, and then only on a Mac with at least one megabyte of memory - more would be better. In addition, stacks can consume huge amounts of storage space (the Help stacks that come with HyperCard are a whopping $736 \mathrm{~kb}$ ) so a two-800K-drive 
system is an absolute minimum, and a hard disk is highly advisable. Don't even dream of trying to use it with a single-drive Mac. You'll end up with "swapper's elbow" from inserting and removing disks so many times.

HyperCard does have room for improvement, in a number of small ways. It would be nice, for example, to mix italic and bold type with normal type (as it, you can make all the type in a field normal, italic, or bold, but you cannot select certain words to have those characteristics). But that's quibbling. The poor educator's mind boggles at the potential of this program as a learning environment, even in its current incarnation. Imagine a stack with the first card having a map of the world. Click anywhere on France, and a map of that country fills the screen. Click on Paris, and get a street map. Move around the map by clicking arrows for adjacent close-up maps until you locate the Louvre, and click on it; the screen fills with a menu of artists' names. Any name selected is replaced with a pop-up menu of titles. Finally, choosing a single tide brings a graphic of the work of art onto the screen.

Couple. HyperCard with an optical or digital disk (which of course, can be done easily), and whole worlds of information-delivery potential open up.

Keep an eye on this program -it's going to have a profound effect on how information is stored, disseminated, and (especially) used. A number of share-ware stacks on a wide variety of topics are now available on computer networks; more will be forthcoming over the next 12-18 months. Several commercial stacks are now available, and we can expect a great many more of these soon.

The author of HyperCard (Bill Atkinson, who created MacPaint) wanted to put programming power into the hands of non-programmers. I think he's succeeded. It's an exciting time to be an educator. 


\section{From the Educational Communication and Technology Periodicals Richard Ellis, Editor}

This column is an edited listing of articles that have appeared recently in the literature of educational communication and technology.

Classroom Computer Learning, 8 (1). September, 1987.

Brady, H. "Tandy fills out its 1000 line."

Coburn, J. "ICON for schools. And only for schools."

Salpeter, J. "IBM's model 25: The new low-end member of the PS/2 family."

Eiser, L. "Two hundred years later. .."

Classroom Computer Learning, 8 (2). October, 1987.

Olivas, J. "Seeing the big picture with the new LCD screens."

Schleifer, N. "Encouraging educational use of computers."

Krengel, L. "College bound: Searching for the right school."

Divoky, D. "Apple sponsors a new alliance for disabled computer users."

Rosen, M. "But wait, there's more."

Classroom Computer Learning, 8 (3), November/December, 1987.

Eiser, L., \& Salpeter, J. "Where on earth is Washington, D.C."

Divosky, D. "Desktop publishing for the yearbook staff."

Kruse, T. "Finding helpful software reviews."

Olivas, J. "Laser printers: Exotic graphics and other eye-catching output for under $\$ 3,000$."

Computers in Education, 5 (2). October, 1987.

Herriott, J. 'The Nth step: Part II:

"Misisterial thrusts: Part I."

Abtan, P. "Interactive videodiscs: Original research at Simon Fraser University."

Beckman, M. "Computer conferencing at the University of Guelph."

Dvorchik, S., \& Wasylenki, L. "Exploring the world of the solar system."

Richard Ellis is with the D. S. Woods Education Library at the University of Manitoba, Winnipeg, MB.

CJEC, VOL. 17, NO. 1, PAGES 67 - 68, ISSN 0710 - 4340 
Emberly, J. "Mastering primary addition on the computer."

Morgan, P. "Cooperative processing."

Gordon, F. D. "Intrologo: Part II."

Hanke, M. "Customizing the ICON's vocabulary: Part II."

Educational Technology, 27(9), September, 1987.

Kemp, J. E. "Perspectives on the instructional technology (LT.) field."

Locatis, C. N. "Notes on the nature of technology."

Kaufman, R. "It's going to be safe to think big again."

Spitzer, D. R. "Why educational technology has failed."

Komoski, P. K. "Beyond innovation: The systematic integration of technology into the curriculum."

Ainsworth, D. "What century is this anyway? A critical look at technology in in education and training."

Mitchell, D. L. "Where education leaves off and training begins."

Geis, G. L., \& Coscarelli, W. "Why do educational technologists teach when they shouldn't? And how can we teach them not to?"

Rossett, A., \& Garbosky, J. 'The use, misuse, and non-use of technologists in public education."

House, R. S. "High tech and human relations: Can we get them together?"

Spitzer. D. R. "Mega-trends in educational technology."

Educational Technology, 27 (10), October, 1987.

Hannafin, M. H. and others. "Computers in education: Ten myths and ten

Carrier, C. A., \& Sales, G. C. "A taxonomy for the design of computer-based instruction."

Kearsley, G. "Productivity tools for educators."

Romiszowski, A. J. "Expert systems in education and training: Automated job aids or sophisticated instructional media?"

Winn, B. "Instructional design and self-designing systems?"

Becker, A. D. "Instructional television and the talking head."

Tillman, M. H., \& Glynn, S. M. "Writing text that teaches: Historical overview."

Rutbaus, M. A. 'Remember programmed instruction?"

R. J. "Stages in learning, teaching, and media support services."

Dick, W. "Formative evaluation: Prospects for the future."

Journal of Computer-Based Instruction, 14 (3), Summer, 1987.

Hagler, P., \&Knowlton, J. "Invalid implicit assumption in CBI comparison research."

Oshrin, S. E., \& Sidcrs, J. A. "The effect of word predictability on the intelligibility of computer synthesized speech."

Wedman, J. F. "Citation patterns in the computer-based instruction literature." 